\title{
Desempenho em Estatística de estudantes do Ensino Fundamental, no contexto do D-Estat
}

\author{
Statistics performance of elementary and middle school students in the context of D- \\ Estat
}

\author{
Irene Mauricio Cazorla ${ }^{1}$ \\ Miriam Cardoso Utsumi ${ }^{2}$ \\ Eurivalda Santana ${ }^{3}$
}

\begin{abstract}
Resumo
Analisamos o desempenho em Estatística de 1.305 estudantes do $1^{\circ}$ ao $9^{\circ}$ ano, do ensino fundamental, de quatro escolas públicas do interior da Bahia, no âmbito de uma pesquisa colaborativa universidade-escola (D-Estat). Construímos três instrumentos, de acordo com o nível de ensino, dos quais analisamos três questões que envolvem variáveis qualitativas, discretas e contínuas; conversão de dados em língua materna para gráficos de barras simples; leitura em tabelas simples e de dupla entrada; cálculo da média, mediana e moda. Os principais resultados mostram que o desempenho cai substancialmente de um nível para outro, mas dentro de cada nível se observa uma tendência crescente, maior nos anos iniciais, sinalizando estagnação nos anos finais. Os resultados sinalizam que é preciso elaborar sequências de ensino validadas na realidade das escolas, que possibilitem o papel ativo dos estudantes, em seus processos de aprendizagem e, consequentemente, para o letramento estatístico.
\end{abstract}

Palavras-chave: Ensino de Estatística; Ensino Fundamental; estudo diagnóstico; D-Estat.

\begin{abstract}
We analyzed the statistical performance of 1,305 students from $1^{\text {st }}$ to $9^{\text {th }}$ grade, in elementary and middle schools, in four public schools in the state of Bahia-Brazil, in the context of a collaborative university-school research (D-Estat). We built three instruments, according to the education level, from which we analyzed three issues involving qualitative, discrete and continuous variables; conversion of native language data to bar graphs; reading of frequency distribution and two-way tables; calculation of mean, median and mode. The main results show that performance falls substantially from one level to another, but within each school grade there is a growing trend, greater in Elementary School, signaling stagnation in the Middle School. The results indicate the need to elaborate teaching sequences validated in the reality of the schools, which allow the active role of students, in the learning processes and, consequently, for statistical literacy.
\end{abstract}

Keywords: Teaching of statistics; Elementary and middle school; diagnostic study; D-Estat.

Submetido em: 01/10/2019 - Aceito em: 12/02/2020 - Publicado em: 26/05/2020

${ }^{1}$ Doutora em Educação pela Universidade Estadual de Campinas. Professora da Universidade Estadual de Santa Cruz, Brasil. Email: icazorla@uol.com.br.

${ }^{2}$ Doutora em Educação pela Universidade Estadual de Campinas. Professora da Universidade Estadual de Campinas, Brasil. Email: mutsumi@unicamp.br.

3 Doutora em Educação Matemática pela Pontifícia Universidade Católica de São Paulo. Professora da Universidade Estadual de Santa Cruz, Brasil. Email: eurivalda@ hotmail.com. 


\section{Introdução}

A inserção dos conteúdos de Estatística no Ensino Fundamental, no componente curricular de Matemática, no Brasil, foi oficializada, em 1997, com a publicação dos Parâmetros Curriculares Nacionais - PCN (MEC, 1997 e 1998), formando um dos quatro blocos, denominado "Tratamento da Informação". Essa tendência foi ratificada na Base Nacional Comum Curricular - BNCC (MEC, 2018), que incluiu seus conteúdos em uma das cinco unidades temáticas denominada "Probabilidade e Estatística".

Todavia, pautadas na nossa experiência como professoras em cursos de formação inicial e continuada; desenvolvendo pesquisa sobre o ensino e a aprendizagem de Estatística em escolas públicas; construindo materiais didáticos e orientando no Mestrado em Educação Matemática, verificamos que os professores das escolas trabalham pouco esses conteúdos e quando o fazem dão mais importância aos aspectos técnicos e operacionais, com abordagem fragmentada, de caráter reprodutivo, desarticulada de temas sociais e desvinculada da realidade dos estudantes, ocorrendo o "ensinar por ensinar" o "cálculo pelo cálculo", reproduzindo um conhecimento sem sentido para o estudante, como pontuado por Campos, Wodewotzki e Jacobini (2013).

Pensando nessa problemática implementamos a pesquisa intitulada "Desenvolvimento profissional de professores que ensinam Matemática, D-Estat” (Santana \& Cazorla, 2018), ancorada na parceria universidade-escola, com vistas a formação de um grupo colaborativo a fim de verificar a viabilidade de um modelo de formação de professores em serviço, que possam, com autonomia, desenvolver e implementar estratégias de ensino, em particular construir e validar sequências de ensino, que garantam a aprendizagem dos estudantes, no ambiente escolar, respeitando a cultura e os tempos da escola.

Escolhemos a unidade temática de Estatística pela própria demanda dos professores das escolas parceiras, que reconhecem sua importância e fragilidade nos seus conhecimentos e porque a Estatística permite trabalhar conteúdos da própria Matemática, com temas transversais, desde uma perspectiva interdisciplinar, onde o estudante tem um papel ativo na construção de seu aprendizado.

Iniciamos a pesquisa realizando um estudo diagnóstico visando mapear o domínio dos conceitos estatísticos que os estudantes conseguiram desenvolver ao longo dos nove anos de escolarização, de forma a nortear a construção das sequências de ensino. Esse estudo diagnóstico, também, será realizado no final da pesquisa para verificar o quanto esse modelo de formação de professores contribuiu para a aprendizagem dos estudantes.

Para a seleção dos conteúdos estatísticos trabalhados nos reportamos às orientações curriculares para o ensino de Estatística no Ensino Fundamental e os princípios que devem nortear esse ensino, quais sejam: o letramento estatístico, o ciclo investigativo e alguns pressupostos da Educação Matemática Crítica, que sustentam o D-Estat e, os níveis de leitura de gráficos proposto por Curcio (1989) e os de tabelas proposto por Wainer (1992), que nos ajudam na análise das tarefas. A seguir, apresentamos alguns de trabalhos correlatos, que nos 
permitem discutir os resultados; o percurso metodológico, os principais resultados do estudo diagnóstico e, por fim, tecemos algumas considerações.

\section{Orientações curriculares do ensino de Estatística no Ensino Fundamental}

No que se refere aos conhecimentos específicos para a área de Matemática, os PCN estipularam quatro blocos de conteúdos: Números e operações, Espaço e Forma, Grandeza e Medidas e Tratamento da Informação. A BNCC estipulou cinco unidades temáticas: Números, Álgebra, Geometria, Grandezas e Medidas e, Probabilidade e estatística. Os conceitos estatísticos que estavam apresentados no bloco Tratamento da Informação, passaram a compor a unidade temática Probabilidade e Estatística, conforme Tabela 1.

Tabela 1- Conceitos estatísticos indicados nos PCN e na BNCC

\begin{tabular}{|c|c|}
\hline PCN (MEC, 1997 e 1998) & BNCC (MEC, 2018) \\
\hline $\begin{array}{l}\text { - Conceitos básicos da Estatística: população, } \\
\text { amostra, censo, amostragem, variáveis, } \\
\text { tipos de variáveis, dados, frequência e } \\
\text { frequência relativa; } \\
\text { - Coleta, organização e descrição de dados. } \\
\text { - Interpretação e elaboração de listas, } \\
\text { fluxogramas, tabelas simples, de dupla } \\
\text { entrada; } \\
\text { Leitura e construção de gráficos, } \\
\text { pictogramas, setores, barras ou colunas } \\
\text { (simples, lado a lado, empilhadas e } \\
\text { opostas), gráfico de linhas, histograma. e } \\
\text { polígonos de frequência. Sintetizar } \\
\text { informações e elaborar inferências; } \\
\text { Medidas de tendência central (Média, } \\
\text { Mediana e Moda); } \\
\text { Produção de textos escritos, a partir da } \\
\text { interpretação de gráficos e tabelas. }\end{array}$ & $\begin{array}{l}\text { - } \quad \text { Leitura de tabelas e de gráficos de colunas simples; } \\
\text { - } \quad \text { Realizar pesquisa envolvendo variáveis categóricas } \\
\text { e numéricas; } \\
\text { - } \quad \text { Coleta, organização e descrição de dados; } \\
\text { - Interpretação e elaboração de listas, tabelas simples, } \\
\text { de dupla entrada, fluxogramas; } \\
\text { - } \quad \text { Resolver problemas cujos dados estão em tabelas ou } \\
\text { em gráficos; } \\
\text { - } \quad \text { Leitura e construção de gráficos de colunas simples } \\
\text { - } \quad \text { agrupadas, barras, pictóricos, de setores, linhas; } \\
\text { numéricas; } \\
\text { - } \quad \text { Pesquisa amostral e censitária; } \\
\text { Medidas de tendência central (Média, Mediana e } \\
\text { Moda); } \\
\text { Dispersão de dados (amplitude). }\end{array}$ \\
\hline
\end{tabular}

Fonte: MEC (1997, 1998 e 2018).

Os conceitos estatísticos listados no Tabela 1 são praticamente os mesmos nos dois documentos, sendo que a BNCC reforça a necessidade de um trabalho metodológico com a realização de pesquisas desde o $1^{\circ}$ ano até o $9^{\circ}$ ano, com o planejamento e execução de pesquisa amostral voltada para a realidade social. Além disso, é esperado que a escola possibilite desenvolver competências e habilidades para a formação cidadã.

Destacamos que o grupo de pesquisa que desenvolve o D-Estat nas escolas acredita que a Estatística é uma ferramenta poderosa que pode contribuir na formação dos cidadãos, tornando-os capazes de ler o mundo. Para isso, alguns princípios devem ser assumidos para seu ensino como o letramento estatístico, o ciclo investigativo, na perspectiva da Educação Matemática Crítica, isto é, instrumentalizar o cidadão com uma Estatística que lhe seja útil para sua vida pessoal e em sociedade. 


\section{Letramento Estatístico e Educação Matemática Crítica}

O uso dos conceitos e procedimentos da Estatística na leitura e modelagem dos fenômenos que permeiam o mundo tem sido denominado letramento estatístico que, para Gal (2002), vai além do domínio dos procedimentos estatísticos, sendo a competência do cidadão para discutir ou comunicar sua compreensão a respeito das informações, emitir opiniões sobre suas implicações e tecer considerações sobre as conclusões elaboradas.

Esse autor propõe um modelo de letramento estatístico formado por dois componentes: um cognitivo e outro atitudinal. O cognitivo é composto de cinco elementos: letramento, conhecimento estatístico, conhecimento matemático, conhecimento de contexto e capacidade de formular questões críticas. $\mathrm{O}$ atitudinal é composto de dois elementos: postura crítica, crenças e atitudes.

Operacionalizar elementos do modelo de Gal (2002) em sala de aula exige vivenciar toda a lógica das investigações estatísticas, com um enfoque crítico e reflexivo. Sendo assim, concordamos com Cazorla e Santana (2010) quando afirmam que "para letrar estatisticamente o aluno, precisamos também desenvolver o pensamento estatístico, de maneira que o aluno reflita, de forma crítica, sobre todas as fases da pesquisa" (p. 13).

Observa-se ainda que a criticidade está presente nos dois componentes do modelo de Gal (2002), sendo que a capacidade de elaborar questões críticas diz respeito à capacidade de o cidadão questionar se aquele conceito utilizado é adequado ou se poderia ter sido utilizado um outro, enquanto a postura crítica diz respeito à capacidade de se posicionar diante dos resultados da investigação.

Skovsmose (2008) discute o papel social da Matemática em favor da democracia, enxergando o ensino dos conteúdos matemáticos como uma possibilidade de os indivíduos desenvolverem suas capacidades críticas em qualquer contexto.

Acreditamos que a perspectiva de letramento estatístico defendida por Gal (2002), está em sintonia com a perspectiva da Educação Matemática Crítica proposta por Skovsmose (2008) que situa o ensino de Matemática para além do ensino de conteúdos, numa perspectiva de promover nos sujeitos, uma forma de análise crítica da realidade na qual se inserem, colaborando para a emancipação dos estudantes.

A realidade contemporânea se apresenta sob diversas formas de representação. Nas mídias é comum as informações virem expostas em representação tabular ou gráfica. Se a escola pretende de fato contribuir para ampliar a leitura de mundo dos estudantes, necessita fazê-los avançar nos níveis de leitura e interpretação de dados apresentados em diversas representações.

Para analisar o nível de leitura de informações contidas em gráficos recorremos a Curcio (1989) que estipulou três níveis diferenciados de compreensão da leitura de gráficos: "Leitura dos dados", referente à leitura literal dos elementos dos gráficos, não necessitando de que o leitor saiba interpretar os dados para além do que está efetivamente posto e perceptível na representação, tendo um custo cognitivo muito baixo, como por exemplo, 
encontrar o valor mínimo ou o máximo; "Leitura entre os dados": inclui a interpretação e integração dos dados no gráfico e requer a habilidade de comparar quantidades e o uso de outros conceitos matemáticos. Esse tipo de leitura requer, ao menos, um grau de inferência lógica ou pragmática como, por exemplo, identificar em que período houve maior crescimento ou a variável que sofreu maior variação; e a "Leitura além dos dados", que é um nível mais complexo e solicita do leitor uma interpretação global, não apenas dos dados contidos no gráfico, mas do entendimento do fenômeno ou da problemática da qual emergem os dados.

De forma análoga, Wainer (1992) propôs três níveis de compreensão para a leitura e interpretação de tabelas: "Nível elementar", quando o leitor extrai das tabelas dados pontuais, que não exigem qualquer ação de sua comparação e/ou análise; "Nível intermediário", quando o leitor interpola e descobre quais são as relações existentes entre os dados que são mostrados nas tabelas; e, "Nível avançado", quando envolve uma compreensão mais ampla da estrutura dos dados apresentados em sua totalidade, geralmente comparando tendências e analisando relações implícitas nas tabelas.

\section{As pesquisas sobre o desempenho dos estudantes em Estatística}

Cobo e Batanero (2004) avaliaram a compreensão de média aritmética e suas propriedades em 53 estudantes do secundário, que resolveram quatro problemas abertos e concluíram que apesar da ideia de média aparentemente ser simples, os resultados da pesquisa indicaram que os estudantes para serem bem sucedidos devem mobilizar várias ideias numéricas na resolução de problemas, tais como a propriedade distributiva da adição e multiplicação, ou a inversão do algoritmo da média. Além disso, devem discriminar propriedades que sendo válidas para a adição e multiplicação, não podem ser generalizadas para encontrar a média das médias.

Mayén, Cobo, Batanero e Balderas (2007) estudaram a compreensão de média, mediana e moda em 125 estudantes mexicanos, de 17 e 18 anos, e compararam os resultados com os de estudantes espanhóis que tinham 15 e 16 anos e que cursavam o último ano do Ensino Secundário. Dentre os resultados destacamos que as pesquisadoras verificaram que no cálculo da mediana, os estudantes se esquecem de ordenar os dados e que não conseguem encontrar a mediana com número par de dados, pois "não sabem resolver a indeterminação produzida por ter dois valores centrais" (p. 196).

Luna e Carvalho (2019) analisaram o desempenho de 100 estudantes do $6^{\circ}$ e $9^{\circ}$ ano do ensino fundamental e $3^{\circ}$ ano do ensino médio de uma escola particular de Pernambuco em cinco questões sobre média aritmética, envolvendo diferentes significados desse conceito em situações com e sem representação gráfica. Os resultados obtidos evidenciaram que o nível de escolaridade foi um fator determinante no desempenho, e foi considerado abaixo do esperado, destacando-se a dificuldade dos participantes em divisão. Observou-se a que representação gráfica influenciou negativamente o desempenho dos estudantes e que eles concebem equivocadamente a média aritmética como sendo: soma de um conjunto de valores, um 
número que é dividido por dois, o termo central de um conjunto de valores dispostos em ordem crescente (mediana), ou ainda, um número terminado em zero.

Estudos mostram que os equívocos não se limitam aos estudantes. Santos e Branches (2019), por exemplo, investigaram os erros em gráficos estatísticos publicados nos meios de comunicação e encontraram diversos problemas, tais como: ausência do eixo das ordenadas, da escala ou das linhas de grade, barras dos gráficos com larguras e alturas desproporcionais, incompatibilidade dos rótulos dos dados com as medidas apresentadas, omissão do zero e interrupção da escala no início do eixo vertical em gráficos de linhas, entre outros.

Teixeira (2016) realizou uma pesquisa bibliográfica sobre ensino e aprendizagem de conteúdos de Estatística e Probabilidade na Educação Básica. O pesquisador afirma que esses conteúdos contêm elementos bastante atraentes para os estudantes, não apenas por estarem presentes no cotidiano deles, mas também pelo potencial de desenvolvimento de atividades interdisciplinares com a compreensão e apropriação de conceitos próprios da cidadania, como a inserção e a participação social e política.

Outros estudos relacionam, ainda, as investigações do uso do ciclo investigativo e o letramento estatístico. Santana (2016) investigou as percepções de uma turma de $3^{\circ}$ ano do ensino médio de uma escola estadual de Minas Gerais que emergiram após a realização de atividades investigativas em grupos de três ou quatro alunos em que eles escolheram o tema a ser investigado: violência, internet, drogas, consumismo, acessibilidade, bullying e corrupção. Tais temas foram desenvolvidos fazendo-se uso das fases do ciclo investigativo e segundo o pesquisador, favoreceram o desenvolvimento de características do letramento estatístico e da motivação dos estudantes, pois tornaram as atividades mais prazerosas.

Nascimento, Paula e Catarino (2018), utilizaram o ciclo investigativo com alunos do $5^{\circ}$ ano em uma escola pública de Portugal e discutiram os resultados de uma aluna. A aproximação entre realidade e conteúdo permitiu a aprendizagem das frequências (absolutas, relativas e percentagens), além do registro de contagens, construção de tabela e gráfico de barras. Os pesquisadores concluíram que a atividade investigativa no contexto do cotidiano da aluna possibilitou o uso de diferentes registros, tratamento e conversões, que contribuíram para a movimentação dos significados e dos sentidos.

Também com foco no interesse dos estudantes Carvalho, Oliveira e Monteiro (2019) propuseram uma formação docente a 11 professores indígenas dos anos iniciais do ensino fundamental. Os professores planejaram uma investigação sobre os recursos hídricos existentes nas aldeias, discutindo a temática e realizando a coleta de dados por meio de entrevistas com a comunidade. Os resultados evidenciaram que os estudantes vivenciaram uma aprendizagem significativa e crítica, possuíam um senso numérico razoável para exprimir os resultados de pesquisa, pois estimaram quantidades e as representaram por meio de gráficos de setores e de barras. Contudo, os pesquisadores ponderaram que aspectos conceituais específicos na construção de gráficos ainda eram necessários para aprimorar o letramento estatístico dos estudantes, em particular aqueles relacionados com a organização e a sistematização das informações estatísticas e o uso da escala no gráfico de barras. 
DOI: $10.20396 /$ zet.v28i0.8656917

Observa-se neste levantamento, que independente do nível de ensino ou das características culturais dos estudantes, práticas de ensino que privilegiem o uso de temas escolhidos por eles, ou que sejam de seus interesses, trabalhados na perspectiva do ciclo investigativo potencializam o desenvolvimento de conhecimentos estatísticos e da postura crítica que podem contribuir para promover a igualdade social. Essas considerações estarão presentes nas sequências de ensino que planejaremos e desenvolveremos juntamente com os professores no projeto D-Estat.

\section{Percurso metodológico}

A pesquisa envolveu quatro escolas, 65 turmas e 1.305 estudantes distribuídos nos nove anos escolares, do Ensino Fundamental, no interior da Bahia, distribuídos por ano escolar conforme Tabela 2.

Os instrumentos foram delineados para acompanhar o domínio dos conceitos ao longo dos nove anos e levaram em consideração as nuances dos anos escolares, por isso desenvolvemos três instrumentos: um para o $1^{\circ}$ ciclo $\left(1^{\circ}\right.$ ao $3^{\circ}$ ano), outro para o $2^{\circ}$ ciclo $\left(4^{\circ} \mathrm{e}\right.$ $5^{\circ}$ ano) e outro para os anos finais ( $6^{\circ}$ ao $9^{\circ}$ ano).

Nesse trabalho analisamos três questões, comuns aos instrumentos desses três ciclos.

Tabela 2 - Número de sujeitos envolvidos na pesquisa, por ano escolar

\begin{tabular}{|c|c|c|c|c|c|c|}
\hline $\begin{array}{c}\text { Ensino } \\
\text { Fundamental } \\
\end{array}$ & Ciclos (*) & $\begin{array}{c}\text { Ano } \\
\text { escolar }\end{array}$ & $\begin{array}{c}\text { Idade } \\
\text { esperada }\end{array}$ & $\mathrm{N}^{\circ}$ de escolas & $\mathrm{N}^{\mathrm{o}}$ de turmas & $\begin{array}{c}\quad \mathrm{N}^{\mathrm{o}} \text { de } \\
\text { estudantes }\end{array}$ \\
\hline \multirow{5}{*}{ Anos iniciais } & \multirow{3}{*}{$\begin{array}{c}\text { Ciclo da } \\
\text { alfabetização }\end{array}$} & $1^{\mathrm{o}}$ & 6 & 1 & 4 & 47 \\
\hline & & $2^{o}$ & 7 & 1 & 4 & 60 \\
\hline & & $3^{\circ}$ & 8 & 1 & 6 & 102 \\
\hline & \multirow{2}{*}{$4^{\circ}$ e $5^{\circ}$ anos } & $4^{\circ}$ & 9 & 1 & 3 & 59 \\
\hline & & $5^{\circ}$ & 10 & 1 & 5 & 104 \\
\hline \multirow{5}{*}{ Anos finais } & \multirow{4}{*}{$6^{\circ}$ ao $9^{\circ}$ ano } & $6^{\circ}$ & 11 & 3 & 15 & 314 \\
\hline & & $7^{\circ}$ & 12 & 3 & 12 & 248 \\
\hline & & $8^{\circ}$ & 13 & 3 & 10 & 222 \\
\hline & & $9^{\circ}$ & 14 & 3 & 6 & 149 \\
\hline & & Total & & 4 & 65 & 1.305 \\
\hline
\end{tabular}

(*) Embora essa nomenclatura não seja utilizada oficialmente, a utilizamos para facilitar a compreensão do trabalho.

Fonte: acervo do D-Estat.

O instrumento do $1^{\circ}$ ciclo estava composto por três questões, duas com variáveis discretas e uma com qualitativa nominal (Tabela 3). A ordem de grandeza dos números era até 25 e envolvia as operações de adição e divisão, em uma concepção intuitiva do repartir. Os dados foram apresentados na língua materna solicitando a conversão para o registro gráfico e uma tabela simples, solicitando a determinação da soma, o máximo, o mínimo, a moda, a média. Da variável qualitativa foi solicitada a moda e o número de dados.

As três questões do instrumento do $2^{\circ}$ ciclo $\left(4^{\circ}\right.$ e $5^{\circ}$ ano) tinham o mesmo enunciado do instrumento do $1^{\circ}$ ciclo, porém a complexidade se deu por conta da ordem de grandeza dos números que chegou a 50 e porque ao invés de solicitar a extração do mínimo e máximo, 
DOI: $10.20396 /$ zet.v28i0.8656917

solicitamos a mediana. Além disso, na Questão 2 os dados passaram de uma tabela simples para uma tabela de dupla entrada, solicitando a soma por linhas, conforme Tabela 4.

Tabela 3 - Estrutura do instrumento para o $1^{\circ}$ ciclo $\left(1^{\circ}\right.$ ao $3^{\circ}$ ano $)$

\begin{tabular}{|c|c|c|c|c|c|c|}
\hline \multirow{2}{*}{ Questão } & Variável & \multirow{2}{*}{$\begin{array}{c}\text { Natureza da } \\
\text { variável }\end{array}$} & $\begin{array}{c}\text { Ordem de } \\
\text { grandeza / } \\
\text { operações }\end{array}$ & Inicial & Gráfica & $\begin{array}{c}\text { Estatísticas } \\
\text { (medidas resumo) }\end{array}$ \\
\hline Q1 & $\begin{array}{c}\mathrm{N}^{\circ} \text { de bolas de } \\
\text { gude }\end{array}$ & $\begin{array}{c}\text { Discreta } \\
\text { (genuína) }\end{array}$ & $\begin{array}{c}\text { Até 15, adição, } \\
\text { divisão }\end{array}$ & $\begin{array}{c}\text { Língua } \\
\text { materna }\end{array}$ & $\begin{array}{c}\text { Gráfico de } \\
\text { barras simples }\end{array}$ & $\begin{array}{c}\text { Máximo, soma, } \\
\text { moda, média }\end{array}$ \\
\hline Q2 & $\begin{array}{c}\mathrm{N}^{\circ} \text { de } \\
\text { brigadeiros }\end{array}$ & $\begin{array}{c}\text { Discreta } \\
\text { (genuína) }\end{array}$ & $\begin{array}{c}\text { Até 15, adição, } \\
\text { divisão }\end{array}$ & $\begin{array}{c}\text { Tabela } \\
\text { simples }\end{array}$ & & $\begin{array}{c}\text { Soma, mínimo, } \\
\text { moda, média }\end{array}$ \\
\hline Q3 & $\begin{array}{c}\text { Animal de } \\
\text { estimação } \\
\text { favorito }\end{array}$ & $\begin{array}{c}\text { Qualitativa } \\
\text { nominal }\end{array}$ & Até 25, adição & $\begin{array}{c}\text { TDF } \\
\text { simples }\end{array}$ & & $\begin{array}{c}\mathrm{N}^{\circ} \text { de dados } \\
\text { (soma), moda }\end{array}$ \\
\hline
\end{tabular}

Fonte: acervo do D-Estat.

Tabela 4 - Estrutura do instrumento para o $2^{\circ}$ ciclo $\left(4^{\circ}\right.$ e $5^{\circ}$ ano $)$

\begin{tabular}{|c|c|c|c|c|c|c|}
\hline \multirow[b]{2}{*}{ Questão } & \multirow[b]{2}{*}{ Variável } & \multirow{2}{*}{$\begin{array}{l}\text { Natureza da } \\
\text { variável }\end{array}$} & \multirow{2}{*}{$\begin{array}{l}\text { Ordem de } \\
\text { grandeza / } \\
\text { operações }\end{array}$} & \multicolumn{3}{|c|}{ Representação } \\
\hline & & & & Inicial & Gráfica & $\begin{array}{c}\text { Estatísticas } \\
\text { (medidas resumo) }\end{array}$ \\
\hline Q1 & $\begin{array}{c}\mathrm{N}^{\circ} \text { de bolas de } \\
\text { gude }\end{array}$ & $\begin{array}{l}\text { Discreta } \\
\text { (genuína) }\end{array}$ & $\begin{array}{l}\text { Até } 42 \text {, adição } \\
\text { e divisão }\end{array}$ & $\begin{array}{l}\text { Língua } \\
\text { materna }\end{array}$ & $\begin{array}{c}\text { Gráfico de } \\
\text { barras simples }\end{array}$ & $\begin{array}{l}\text { Soma, moda, } \\
\text { média, mediana }\end{array}$ \\
\hline Q2 & \begin{tabular}{|c|}
$\mathrm{N}^{\mathrm{o}} \mathrm{de}$ \\
brigadeiros por \\
dia
\end{tabular} & $\begin{array}{c}\text { Discreta } \\
\text { (genuína) e } \\
\text { qualitativa }\end{array}$ & $\begin{array}{l}\text { Até } 30 \text {, adição } \\
\text { e divisão }\end{array}$ & $\begin{array}{c}\text { Tabela de } \\
\text { dupla } \\
\text { entrada }\end{array}$ & & $\begin{array}{l}\text { Soma, moda, } \\
\text { média e mediana }\end{array}$ \\
\hline Q3 & $\begin{array}{l}\text { Animal de } \\
\text { estimação } \\
\text { favorito }\end{array}$ & $\begin{array}{c}\text { Qualitativa } \\
\text { nominal }\end{array}$ & Até 50 , adição & $\begin{array}{c}\text { TDF } \\
\text { simples }\end{array}$ & & $\begin{array}{l}\mathrm{N}^{\mathrm{o}} \text { de dados, } \\
\text { moda }\end{array}$ \\
\hline
\end{tabular}

Fonte: acervo do D-Estat.

As três questões do instrumento dos anos finais ( $6^{\circ}$ ao $9^{\circ}$ ano) mantinham a mesma estrutura dos instrumentos dos anos iniciais, com algumas mudanças (Tabela 5). Na Questão 1 mudamos apenas o nome da variável. $\mathrm{Na}$ Questão 2, além dos dados estarem em uma tabela de dupla entrada, solicitamos a soma e média das linhas e das colunas, uma propriedade da média e comparação. Na Questão 3 passamos de uma TDF simples para uma TDF de dupla entrada, solicitando a frequência relativa e a percepção de relações entre variáveis.

Tabela 5 - Estrutura do instrumento para os anos finais $\left(6^{\circ}\right.$ ao $9^{\circ}$ ano $)$

\begin{tabular}{|c|c|c|c|c|c|c|}
\hline Questão & Variável & $\begin{array}{c}\text { Natureza da } \\
\text { variável }\end{array}$ & $\begin{array}{c}\text { Ordem de } \\
\text { grandeza / } \\
\text { operações }\end{array}$ & Inicial & Gráfica & $\begin{array}{c}\text { Estatísticas } \\
\text { (medidas resumo) }\end{array}$ \\
\cline { 6 - 7 } Q1 & $\begin{array}{c}\text { Valor gasto } \\
\text { na padaria }\end{array}$ & $\begin{array}{c}\text { Contínua } \\
\text { (discretizada) }\end{array}$ & $\begin{array}{c}\text { Até 50, adição, } \\
\text { divisão, ordenação }\end{array}$ & Lista & $\begin{array}{c}\text { Gráfico de } \\
\text { barras simples }\end{array}$ & $\begin{array}{c}\text { Soma, moda, } \\
\text { média, mediana }\end{array}$ \\
\hline Q2 & $\begin{array}{c}\text { Notas dos } \\
\text { estudantes } \\
\text { em duas } \\
\text { provas }\end{array}$ & $\begin{array}{c}\text { Contínua } \\
\text { (discretizada), } \\
\text { qualitativa }\end{array}$ & $\begin{array}{c}\text { Até 50, adição, } \\
\text { divisão }\end{array}$ & $\begin{array}{c}\text { Tabela de } \\
\text { dupla entrada }\end{array}$ & $\begin{array}{c}\text { Soma, média, } \\
\text { propriedade da } \\
\text { média, } \\
\text { comparação }\end{array}$ \\
\hline $\begin{array}{c}\text { Animal de } \\
\text { estimação } \\
\text { favorito por } \\
\text { gênero }\end{array}$ & $\begin{array}{c}\text { quas } \\
\text { qualitativas } \\
\text { nominais }\end{array}$ & $\begin{array}{c}\text { Até 200, adição, } \\
\text { divisão }\end{array}$ & $\begin{array}{c}\text { TDF de dupla } \\
\text { entrada }\end{array}$ & & $\begin{array}{c}\mathrm{N}^{\circ} \text { de dados, } \\
\text { moda, freq. } \\
\text { relativa }(\%)\end{array}$ \\
\hline
\end{tabular}

Fonte: acervo do D-Estat. 
Como podemos observar o último instrumento é mais complexo que os anteriores, pois solicitamos leitura para além dos dados. Todavia, contempla apenas as habilidades preconizadas pela BNCC e, portanto, é esperado que tais conteúdos sejam de domínio dos estudantes. Uma questão importante era saber se os estudantes conheciam os nomes das medidas de tendência central (MTC), por isso perguntamos explicitamente.

Todos os procedimentos éticos da pesquisa com seres humanos foram seguidos, tais como o preenchimento do Termo de Consentimento Livre e Esclarecido (TCLE), autorização da direção da escola, dentre outros.

O instrumento foi respondido entre maio e junho de 2018. Os estudantes estavam no início do ano letivo (greve e atraso do ano letivo) e responderam o instrumento de forma individual, no horário da aula, com supervisão do professor da turma, a quem foi solicitado não interferir nas respostas dos estudantes.

As respostas foram categorizadas em corretas e não corretas (erradas e em branco) e criamos a variável "porcentagem de acerto", os dados foram transcritos para uma planilha eletrônica.

\section{Resultados e discussão}

Nesta seção apresentamos os resultados em três subseções de acordo com os ciclos e na quarta seção traçamos um paralelo desses três ciclos.

\section{Desempenho dos estudantes do $1^{\circ}$ ciclo $\left(1^{\circ}\right.$ ao $3^{\circ}$ ano $)$}

A Questão 1 (Figura 1), apresentava uma variável discreta, com cinco dados na língua materna e solicitava seis tarefas: conversão dos dados para um gráfico de barras, disponibilizando o arcabouço do gráfico (G.Barras); identificar a criança que possuía o valor máximo (Máximo)"; o valor máximo (MaxValor)"; o total de gudes (Soma); identificar a moda (Moda) e, calcular a média (Média), sendo que a moda e média foram solicitadas sem mencionar essa nomenclatura.

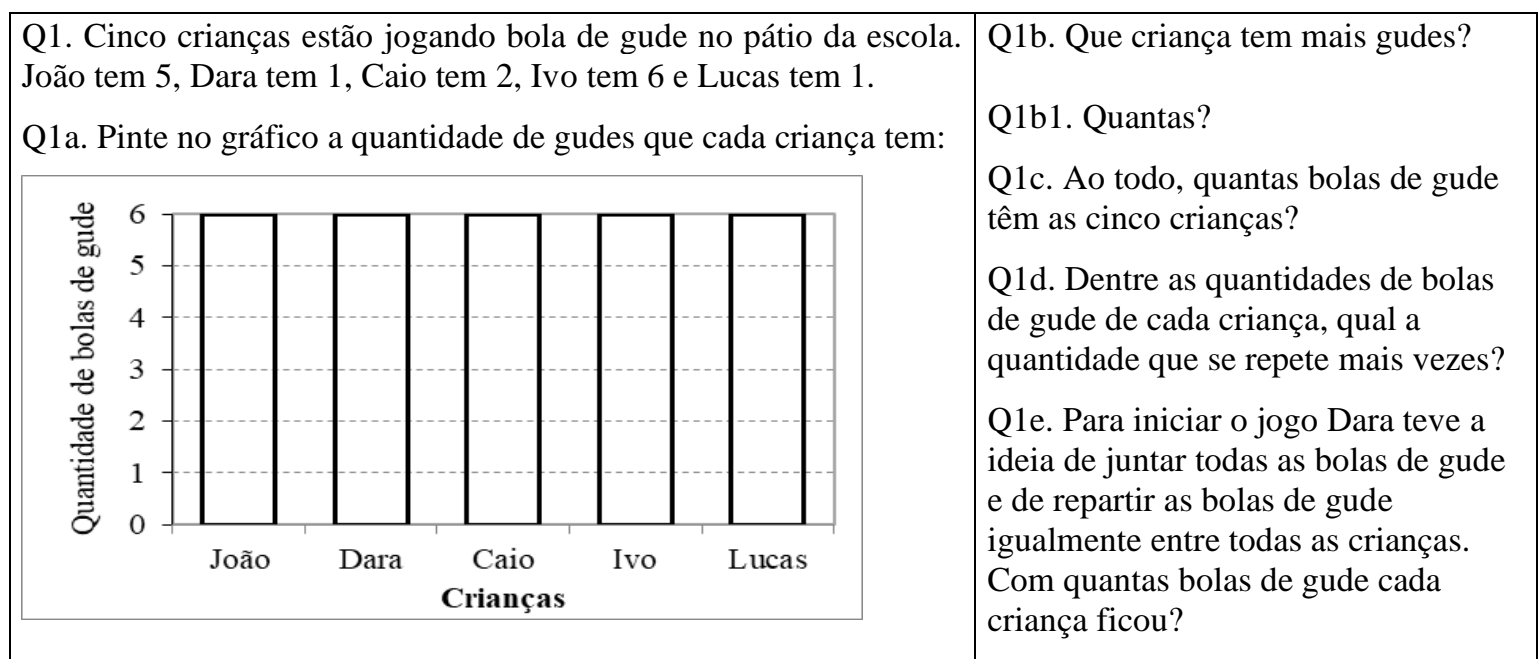

Figura 1 - Enunciado da Questão 1 do $1^{\circ}$ ciclo. 
DOI: $10.20396 /$ zet.v28i0.8656917

Fonte: acervo do D-Estat.

$\mathrm{Na}$ Figura 2 podemos verificar que o desempenho aumenta com a escolaridade em todos os conceitos, com exceção da Moda e na determinação do máximo. Em geral, os estudantes do $1^{\circ}$ ano apresentam um desempenho inferior. Nas tarefas em que se solicitavam a leitura de dados, sem fazer cálculos (Máximo e Moda), o desempenho foi acima de 50\%, o pior desempenho foi no cálculo da média, em especial no $1^{\circ}$ ano.

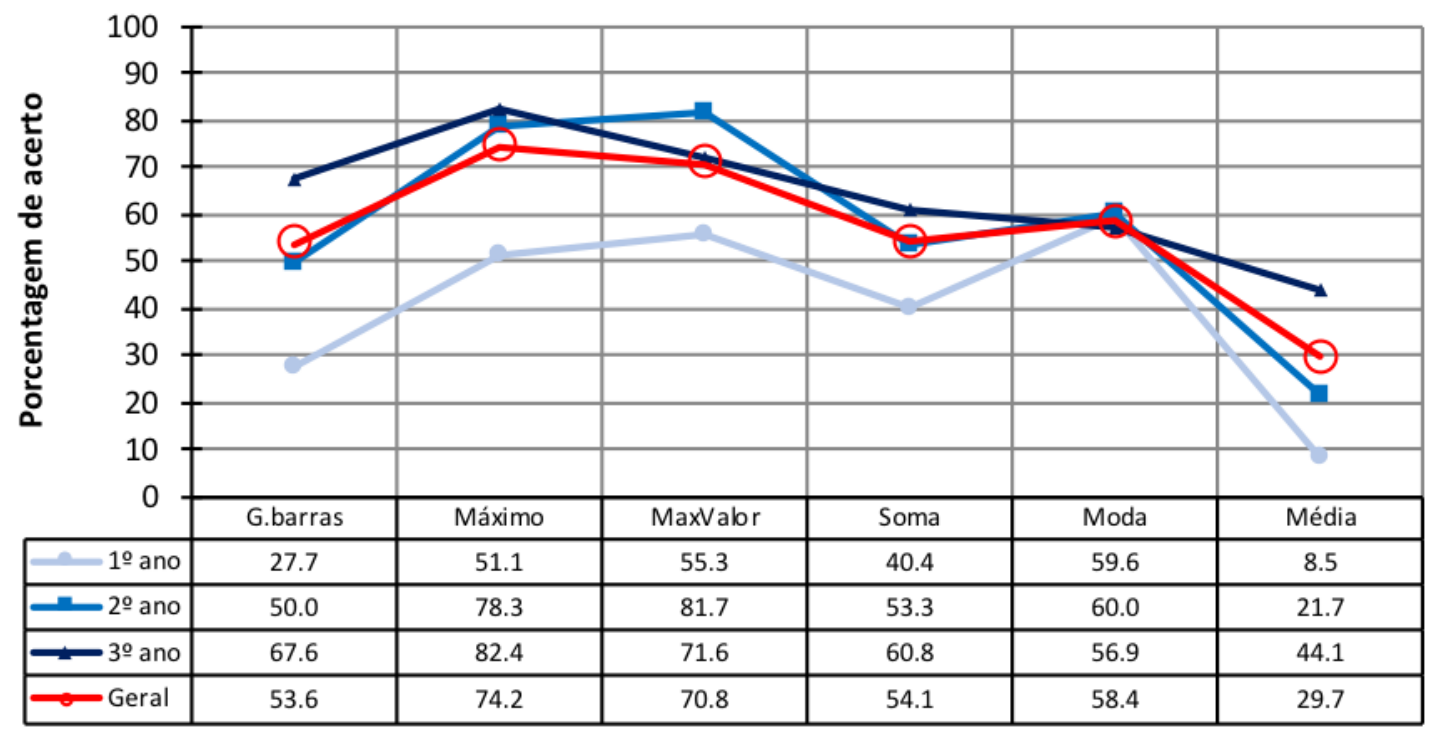

Figura 2 - Porcentagem de acerto dos estudantes do $1^{\circ}$ ciclo na Questão 1, por ano escolar. Fonte: acervo do D-Estat.

A Questão 2 (Figura 3) apresentava uma variável discreta, com quatro dados dispostos em uma tabela simples e solicitava seis tarefas: o total (SomaC); identificar a criança que comeu menos (Mínimo); o valor mínimo (MinValor); identificar a moda implícita (Moda); identificar o valor da moda (ModaVal) e efetuar a divisão em partes iguais (Média).

\begin{tabular}{|c|c|}
\hline \multicolumn{2}{|c|}{$\begin{array}{l}\text { Q2. A Vovó Maria preparou brigadeiros para os set } \\
\text { netos, não sobrou nenhum! Ela contou quanto } \\
\text { brigadeiros cada neto comeu e anotou na tabela a seguir } \\
\text { Quadro } 1 \text { - Quantidade de brigadeiros que cada neto } \\
\text { comeu }\end{array}$} \\
\hline Netos & Número de brigadeiros \\
\hline Clara & 3 \\
\hline Luiz & 4 \\
\hline Bia & 1 \\
\hline Nina & 4 \\
\hline Total de brigadeiros & \\
\hline
\end{tabular}

Q2a. Quantos brigadeiros a vovó preparou ao todo?

Q2b. Quem comeu a menor quantidade de brigadeiros?

Q2c. Quantos brigadeiros comeu?

Q2d. Teve netos que comeram a mesma quantidade de brigadeiros?

Q2e. Se sim, quantos brigadeiros comeu cada um?

Q2f. Se a Vovó tivesse dito que todos os netos deveriam comer a mesma quantidade de brigadeiros, quantos cada um deveria comer?

Figura 3 - Enunciado da Questão 2 do $1^{\circ}$ ciclo.

Fonte: acervo do D-Estat.

Na Figura 4 observamos que os estudantes dos três anos apresentam um bom desempenho, inclusive os do $1^{\circ}$ ano, sinalizando que os estudantes possuem o nível elementar 
DOI: $10.20396 /$ zet.v28i0.8656917

de leitura de tabelas (Wainer, 1992) e que o fato de os dados estarem em língua materna ou tabela simples não interferiu no desempenho.

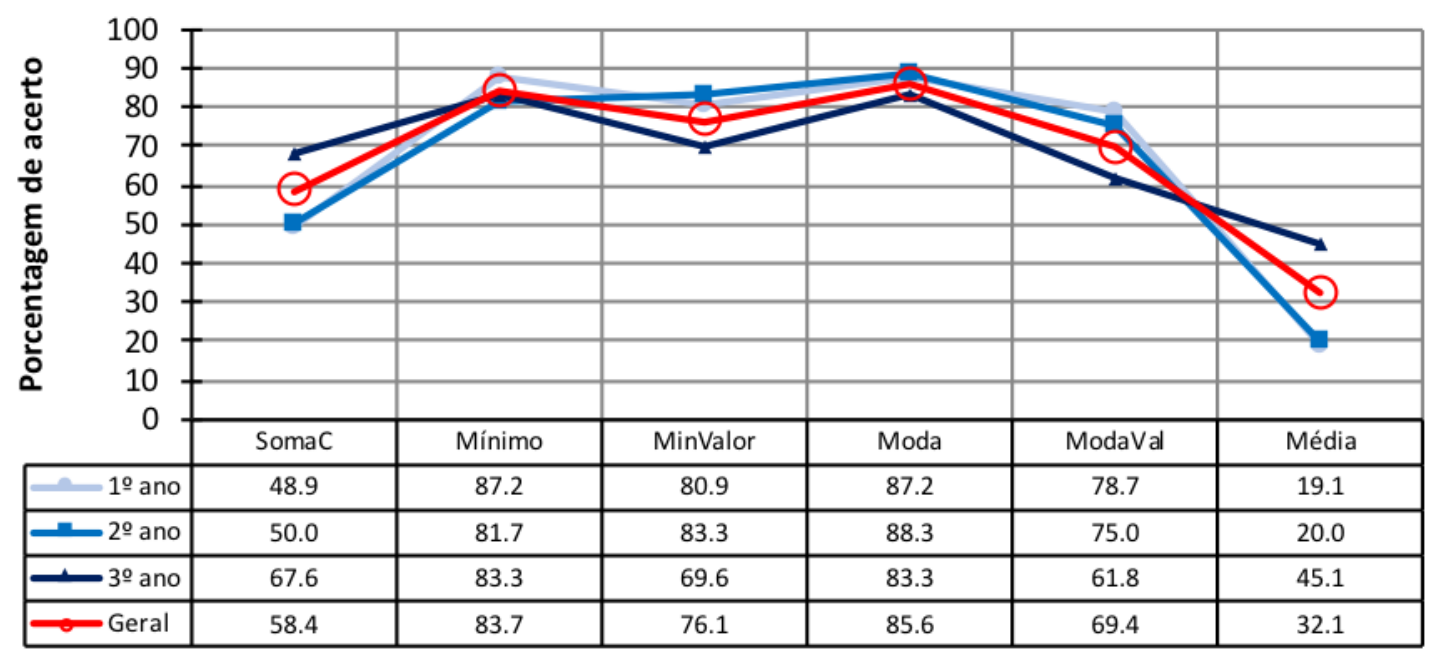

Figura 4 - Porcentagem de acerto dos estudantes do $1^{\circ}$ ciclo na Questão 2, por ano escolar.

Fonte: acervo do D-Estat.

A Questão 3 (Figura 5) apresentava uma variável qualitativa em uma TDF e solicitava duas tarefas: "Quantos estudantes responderam à pergunta?" (Soma) e, "Qual é o animal de estimação favorito que a maioria dos estudantes escolheu?" (Moda).

Os resultados apresentados na Figura 6 confirmam que os participantes possuem o nível elementar de leitura de tabela, pois para identificar o animal favorito precisavam procurar o valor máximo (frequência modal) e associar a categoria (cachorro). A maioria dos estudantes não conseguiu sequer realizar a soma para encontrar quantos estudantes responderam à pergunta.

Q3. A professora da escola perguntou aos estudantes qual era o animal de estimação favorito e ela organizou os dados no quadro a seguir:

Quadro 2-Quantidade de estudantes segundo o animal de estimação favorito

\begin{tabular}{|c|c|}
\hline Animal de estimação favorito & $\begin{array}{c}\text { Número de } \\
\text { estudantes }\end{array}$ \\
\hline Gato & 7 \\
\hline Passarinho & 2 \\
\hline Cachorro & 8 \\
\hline Tartaruga & 3 \\
\hline Outros (macaco, mico leão etc.) & 3 \\
\hline Nenhum & 2 \\
\hline Total de estudantes & \\
\hline
\end{tabular}

Figura 5 - Enunciado da Questão 3 do $1^{\circ}$ ciclo.

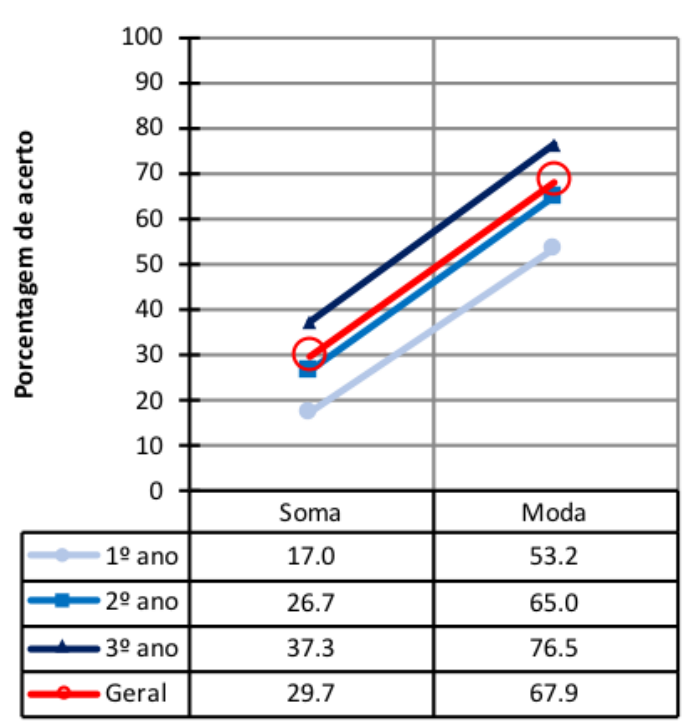

Figura 6 - Porcentagem de acerto dos estudantes do $1^{\circ}$ ciclo na Questão 3, por ano escolar.

Fonte: acervo do D-Estat. 

Figura 7.

Finalizando a análise do desempenho dos estudantes dos anos iniciais apresentamos a

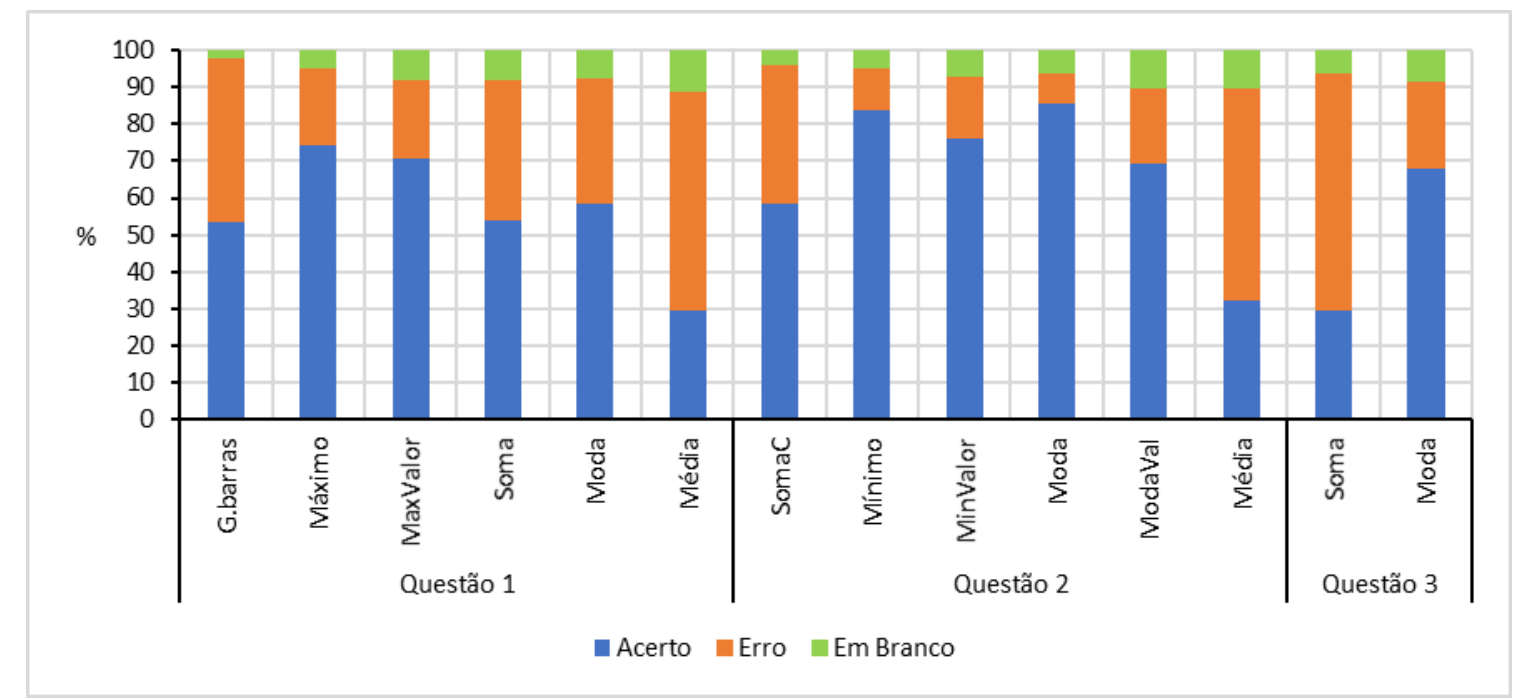

Figura 7 - Distribuição percentual do acerto, erro e em branco, por item, dos estudantes do $1^{\circ}$ ciclo. Fonte: acervo do D-Estat.

Observa-se que a porcentagem de respostas em branco em cada item é inferior a $10 \%$ e o conceito de repartir em partes iguais foi o que apresentou mais respostas em branco (Q1f Média) e (Q2f-Média). Esse resultado parece razoável tendo em vista que nos anos iniciais o conceito de divisão é um dos últimos a ser ensinado e sua consolidação leva um tempo maior que o da adição, subtração e multiplicação.

Desempenho dos estudantes do segundo ciclo $\left(4^{\circ}\right.$ e $5^{\circ}$ ano)

A Questão 1 tinha o mesmo enunciado do instrumento do $1^{\circ}$ ciclo, aumentando a quantidade de dados de 5 para 7 e os valores: "Sete crianças estão jogando bola de gude no pátio da escola. João tem 4, Dara tem 6, Caio tem 4, Ivo tem 10, Lucas tem 9, Ana tem 4 e Enzo tem 5". Os itens solicitavam: converter os dados da língua materna para um gráfico de barras (G.Barras); encontrar o total de bolas de gude (Soma); identificar o valor que se repete com mais frequência (Moda); dividir em partes iguais (Média), ordenar (Ordem) e encontrar o valor que ocupa a posição central (Mediana).

Na Figura 8 verificamos que, no geral, os estudantes se saíram melhor na conversão dos dados da língua materna para o registro gráfico e na moda; porém, apenas metade conseguiu somar as quantidades e menos de um terço conseguiu encontrar a média. Esperávamos que a tarefa de ordenação fosse relativamente simples, todavia menos de 42,3\% conseguiu realizar; igualmente, esperávamos que encontrar a Mediana fosse uma tarefa intuitiva e fácil, uma vez que encontrar a posição central era imediata, pois o número de dados era sete (ímpar), bastando ler o valor do dado que ocupava a $4^{a}$ posição; todavia, menos de um quarto dos estudantes conseguiu realizar essa tarefa. Como no $1^{\circ}$ ciclo, observamos que os alunos do $4^{\circ}$ e $5^{\circ}$ ano apresentam dificuldades em todos os itens que necessitam realizar algum cálculo. 
DOI: $10.20396 /$ zet.v28i0.8656917

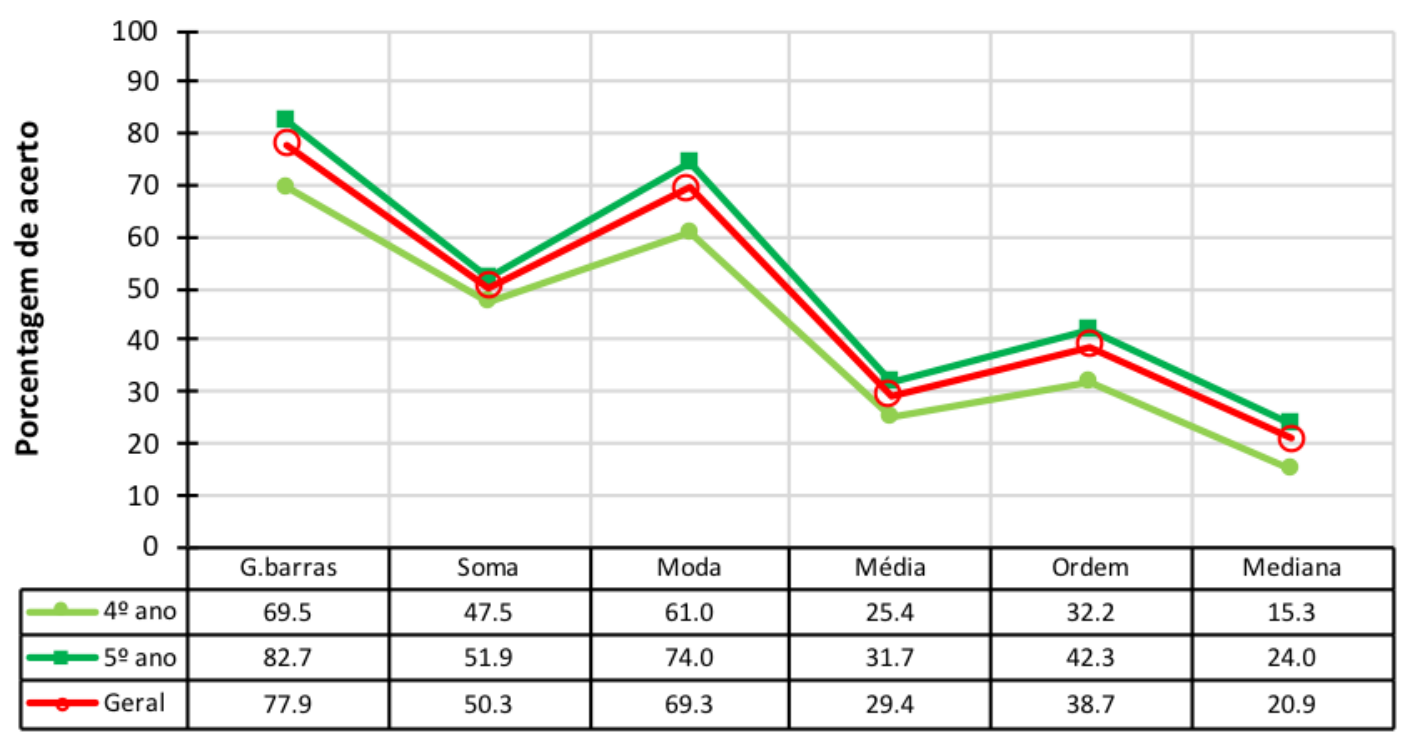

Figura 8 - Porcentagem de acerto dos estudantes do $2^{\circ}$ ciclo na Questão 1, por ano escolar. Fonte: acervo do D-Estat.

A Questão 2 (Figura 9) era similar à do $1^{\circ}$ ciclo, porém os dados estavam em uma tabela de dupla entrada solicitando oito tarefas: somar os valores das linhas (Soma L); somar os valores das colunas (SomaC); ordenar o total de brigadeiros (Ordem); encontrar o valor que ocupa a posição central (Mediana), e três médias (Média1, Média2, Média3).

\begin{tabular}{|c|c|c|c|}
\hline \multirow{2}{*}{\multicolumn{4}{|c|}{$\begin{array}{l}\text { Q2. A Vovó Maria preparou brigadeiros para os } \\
\text { seus netos, no final de semana e não sobrou } \\
\text { nenhum! Ela contou quantos brigadeiros cada } \\
\text { neto comeu em cada dia e anotou no quadro a } \\
\text { seguir: } \\
\text { Quadro } 1 \text { - Quantidade de brigadeiros que cada } \\
\text { neto comeu no final de semana }\end{array}$}} \\
\hline & & & \\
\hline \multirow{2}{*}{ Netos } & \multicolumn{3}{|c|}{$\begin{array}{l}\text { Quantidade de brigadeiros que } \\
\text { cada neto comeu }\end{array}$} \\
\hline & Sábado & Domingo & $\begin{array}{l}\text { no final de } \\
\text { semana }\end{array}$ \\
\hline Clara & 4 & 5 & \\
\hline Luiz & 5 & 6 & \\
\hline $\mathrm{Bia}$ & 3 & 5 & \\
\hline Nina & 0 & 0 & \\
\hline $\begin{array}{l}\text { Total de } \\
\text { brigadeiros }\end{array}$ & & & \\
\hline
\end{tabular}

Q2a. Preencha o quadro com o total de brigadeiros que cada neto comeu no final de semana.

Q2b. Preencha o quadro com o total de brigadeiros consumidos no sábado, no domingo e no final de semana.

Q2c. Coloque em ordem crescente o número de brigadeiros consumidos pelos netos no final de semana:

\begin{tabular}{|l|l|l|l|}
\hline $1^{\mathrm{a}}$ posição & $2^{\mathrm{a}}$ posição & $3^{\mathrm{a}}$ posição & $4^{\mathrm{a}}$ posição \\
\hline & & & \\
\hline
\end{tabular}

Q2d. Qual é a quantidade de brigadeiros que ocupa a posição central?

Q2e. Se a Vovó tivesse dito que todos os netos deveriam comer a mesma quantidade de brigadeiros, quantos brigadeiros cada um deveria comer: no sábado?

Q2f. No domingo?

Q2g. No final de semana?

Figura 9 - Enunciado da Questão 2 do $2^{\circ}$ ciclo ( $4^{\circ}$ e $5^{\circ}$ ano).

Fonte: acervo do D-Estat.

Na Figura 10 podemos observar que a maioria dos estudantes conseguiu realizar a soma por linha; mas na soma por coluna o desempenho caiu para menos de um terço. A ordenação não superou 40\%; praticamente nenhum estudante conseguiu encontrar o valor central, o que sinaliza que a mediana para número de dados par não é intuitiva e precisa de 
DOI: $10.20396 /$ zet.v28i0.8656917

instrução. Encontrar as três médias ficou em torno de $25 \%$, o que consideramos um resultado insatisfatório, uma vez que a ordem de grandeza dos números era pequena, assim como a quantidade de dados.

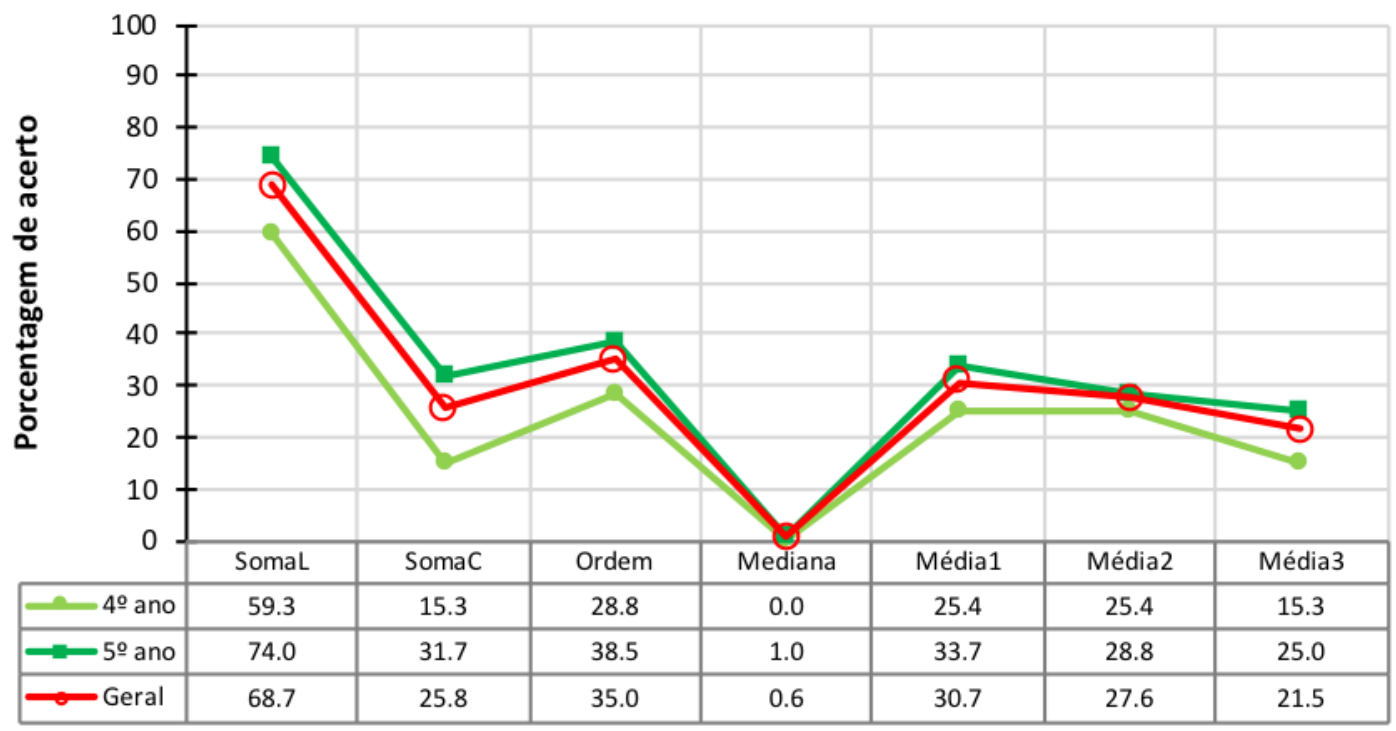

Figura 10 - Porcentagem de acerto dos estudantes do $2^{\circ}$ ciclo na Questão 2, por ano escolar. Fonte: acervo do D-Estat.

A Questão 3 era similar à do $1^{\circ}$ ciclo, com números ligeiramente maiores. No caso da moda, verificamos que apenas $42,4 \%$ no $4^{\circ}$ ano e $76,9 \%$ no $5^{\circ}$ ano conseguiram identificá-la. Quanto à soma verificamos que apenas $18,6 \%$ do $4^{\circ}$ ano e $26 \%$ do $5^{\circ}$ ano conseguiram somar corretamente os seis números, o que indica desempenho inferior ao do $1^{\circ}$ ciclo.

Finalizando a análise do desempenho dos estudantes do $2^{\circ}$. ciclo apresentamos a Figura 11.

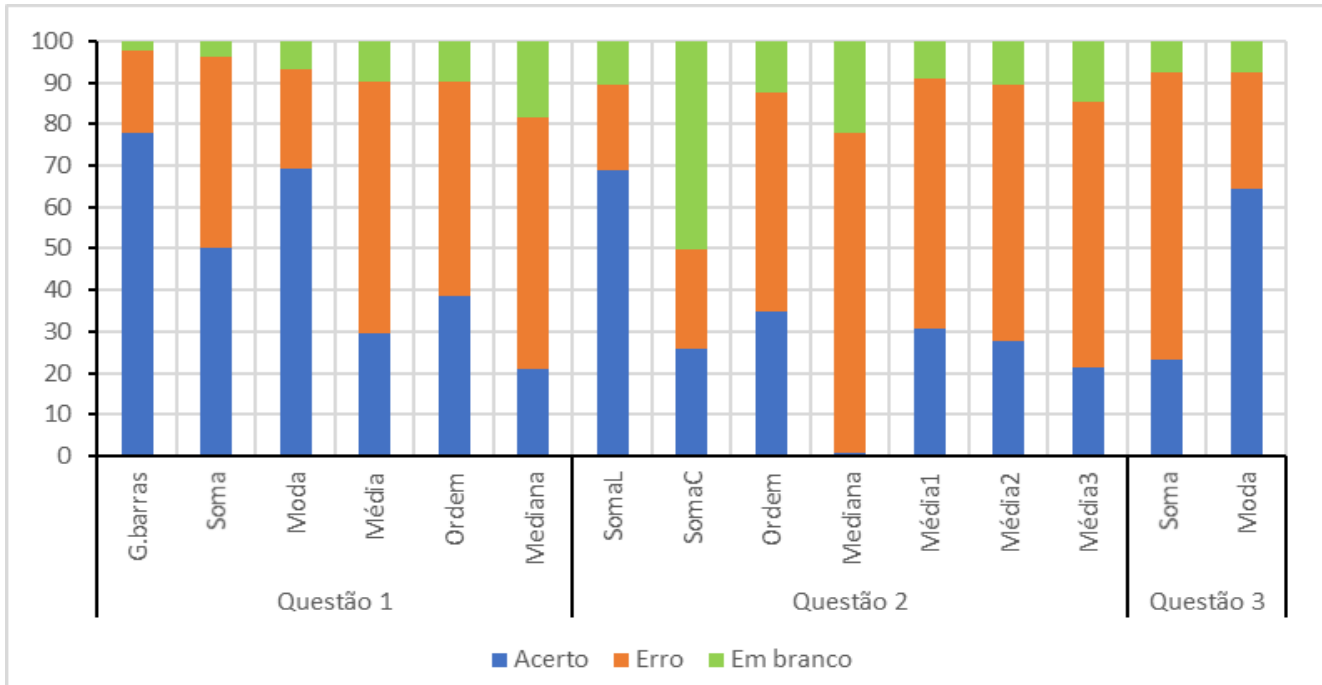

Figura 11 - Distribuição percentual do acerto, erro e em branco, por item, dos estudantes do $2^{\circ}$ ciclo. Fonte: acervo do D-Estat. 
DOI: $10.20396 /$ zet.v28i0.8656917

Observamos que o número de respostas em branco aumentou consideravelmente com relação ao $1^{\circ}$ ciclo e o item que se destacou foi o que solicitava a quantidade de brigadeiros consumidos no sábado, no domingo e no final de semana (Q2b-SomaC), que exigia a soma de valores pequenos. Acreditamos que, nesse caso, a representação tabular foi um obstáculo, pois apresentava vários dados, em várias colunas, o que não é uma forma usual na escola.

\section{Desempenho dos estudantes dos anos finais do Ensino Fundamental}

A Questão 1 tinha estrutura similar a do instrumento do $2^{\circ}$ ciclo, mudando apenas o nome da variável: "O avô de Danilo gastou na padaria, durante a semana passada, como apresentado na lista a seguir (seguida dos dias da semana e os valores gastos de segunda-feira a domingo: 4, 4, 4, 5, 6, 10, 9)". Foram solicitadas nove tarefas: converter os dados da lista para um gráfico de barras (G.Barras); encontrar o total gasto (Soma); identificar o valor que se repete com mais frequência (Moda); explicitar o nome da moda (N_Moda); dividir o total gasto pelos sete dias: "Na próxima semana, o avô de Danilo gastará o mesmo valor, mas em quantias iguais todos os dias. Quanto ele gastará em cada dia? (Média); explicitar o nome da média (N_Média), ordenar os valores (Ordem); encontrar o valor que ocupa a posição central (Mediana) e explicitar o nome da Mediana (N_Mediana).

Na Figura 12 verificamos que os estudantes se saíram melhor na conversão dos dados para a representação gráfica e na realização da soma. Na determinação da moda verificamos uma variação muito grande chegando apenas à 53\%, o mesmo na média, que sequer chega a $27,9 \%$. O desempenho na mediana não superou 32,2\%. Os resultados indicam estagnação do desempenho em relação à escolaridade.

Quanto aos nomes das MTC, praticamente nenhum estudante sabia. Observamos que a maioria dos estudantes errou na ordenação, uma vez que os dados estavam ordenados até o penúltimo elemento, o que pode ter induzido ao erro. Contudo, esse fato não interferiu na determinação da Mediana, pois a posição central se manteve inalterada e, por essa razão, o desempenho foi um pouco melhor que na ordenação.

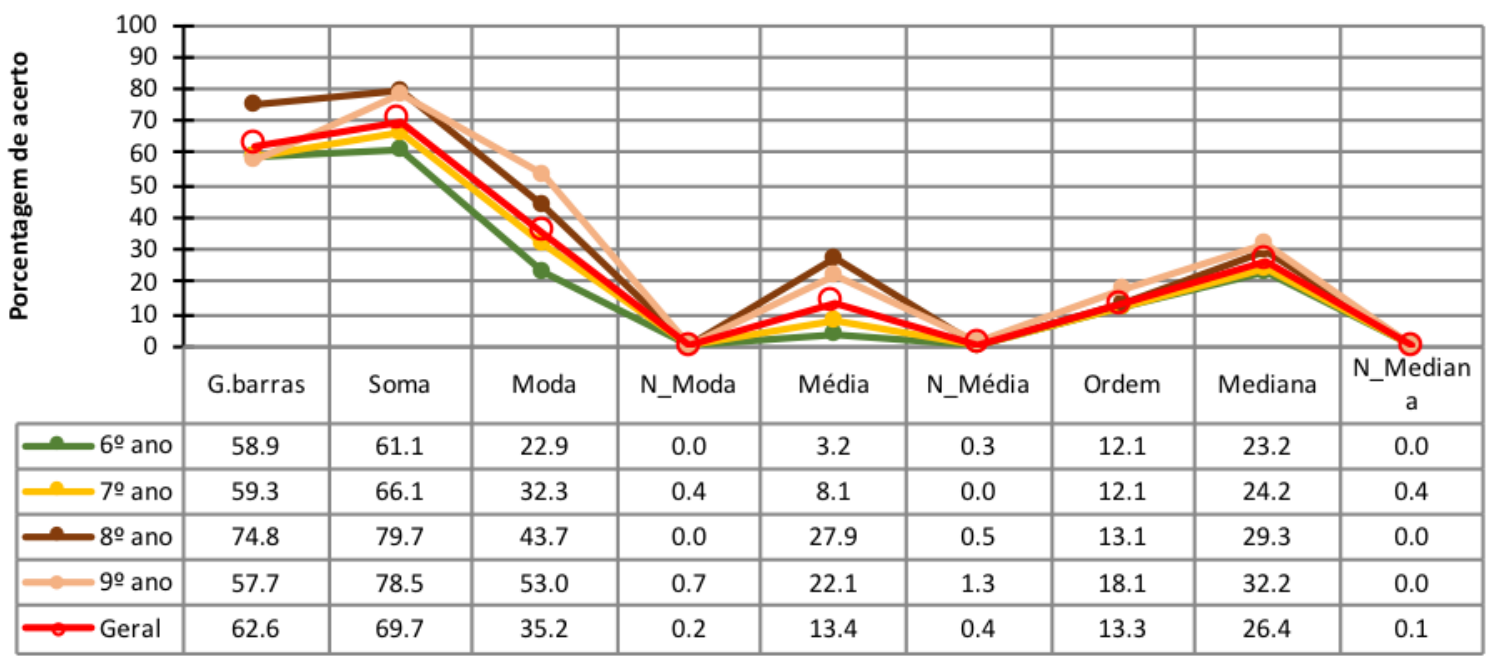

Figura 12 - Porcentagem de acerto dos estudantes dos anos finais na Questão 1, por ano escolar. Fonte: acervo do D-Estat. 
DOI: $10.20396 /$ zet.v28i0.8656917

A Questão 2 (Figura 13) era similar à do $2^{\circ}$ ciclo, com a diferença que além da soma das linhas foi solicitado de forma explícita o cálculo da média, das linhas e das colunas. As nove tarefas foram: soma e média por linhas (MédiaL); soma por colunas (SomaC)"; média na $1^{\text {a }}$ prova (Média1); média na $2^{\text {a }}$ prova (Média2); a média nas duas provas (Média3); comparar as médias dos estudantes com o limite estabelecido e tomar decisão (Comparação1)"; propriedade da média (Prop.Média); quantificar o impacto na média (Quanto), e por fim, novamente comparação e tomada de decisão (Comparação2).

Q2. A nota em Matemática de um grupo de cinco
estudantes se encontra a seguir.
Quadro 1 - Nota de cinco estudantes nas duas provas
\begin{tabular}{|l|c|c|c|c|}
\hline Estudante & $\begin{array}{c}1^{\mathrm{a}} \\
\text { prova }\end{array}$ & $\begin{array}{c}2^{\mathrm{a}} \\
\text { prova }\end{array}$ & $\begin{array}{c}\text { Total } \\
\text { nas duas } \\
\text { provas }\end{array}$ & $\begin{array}{c}\text { Média } \\
\text { das duas } \\
\text { provas }\end{array}$ \\
\hline Bia & 7 & 3 & & \\
\hline Luiz & 7 & 3 & & \\
\hline Cléo & 8 & 4 & & \\
\hline Nina & 6 & 2 & & \\
\hline João & 7 & 3 & & \\
\hline $\begin{array}{l}\text { Total de pontos } \\
\text { do grupo }\end{array}$ & & & & \\
\hline
\end{tabular}

Q2a. Preencha no quadro o total de pontos nas duas provas e a média da nota de cada estudante.

Q2b. Preencha no quadro o total de pontos do grupo na $1^{\mathrm{a}}$ prova e na $2^{\mathrm{a}}$ prova.

Q2c. Qual foi a média do grupo na $1^{\mathrm{a}}$ prova?

Q2d. Qual foi a média do grupo na $2^{\mathrm{a}}$ prova?

Q2e. Qual foi a média do grupo nas duas provas?

Q2f. Se a nota mínima para aprovar na disciplina for 6 , quantos estudantes estariam aprovados?

Q2g. A Professora verificou que uma questão da segunda prova estava errada e decidiu acrescentar dois pontos à nota de todos os estudantes. $\mathrm{O}$ que acontece com a média da segunda prova? Em quanto?

Q2h. Neste caso, quantos estudantes estariam aprovados?

Figura 13 - Enunciado da Questão 2 dos anos finais.

Fonte: acervo do D-Estat.

Na Figura 14 verificamos que os estudantes apresentaram pior desempenho no cálculo das médias por linha (somar e dividir por dois) e das provas (dividir por 5). Menos da metade consegui realizar a soma das colunas. $O$ fracasso na média geral dificultou realizar as comparações. Observamos, também, que poucos estudantes perceberam que o aumento da nota na $2^{\mathrm{a}}$ prova em dois pontos aumentaria a média na $2^{\mathrm{a}}$ prova em dois pontos, e que isso impactaria em um ponto na média geral, uma vez que eram duas notas. Nesta tarefa poucos estudantes conseguiram sucesso. 


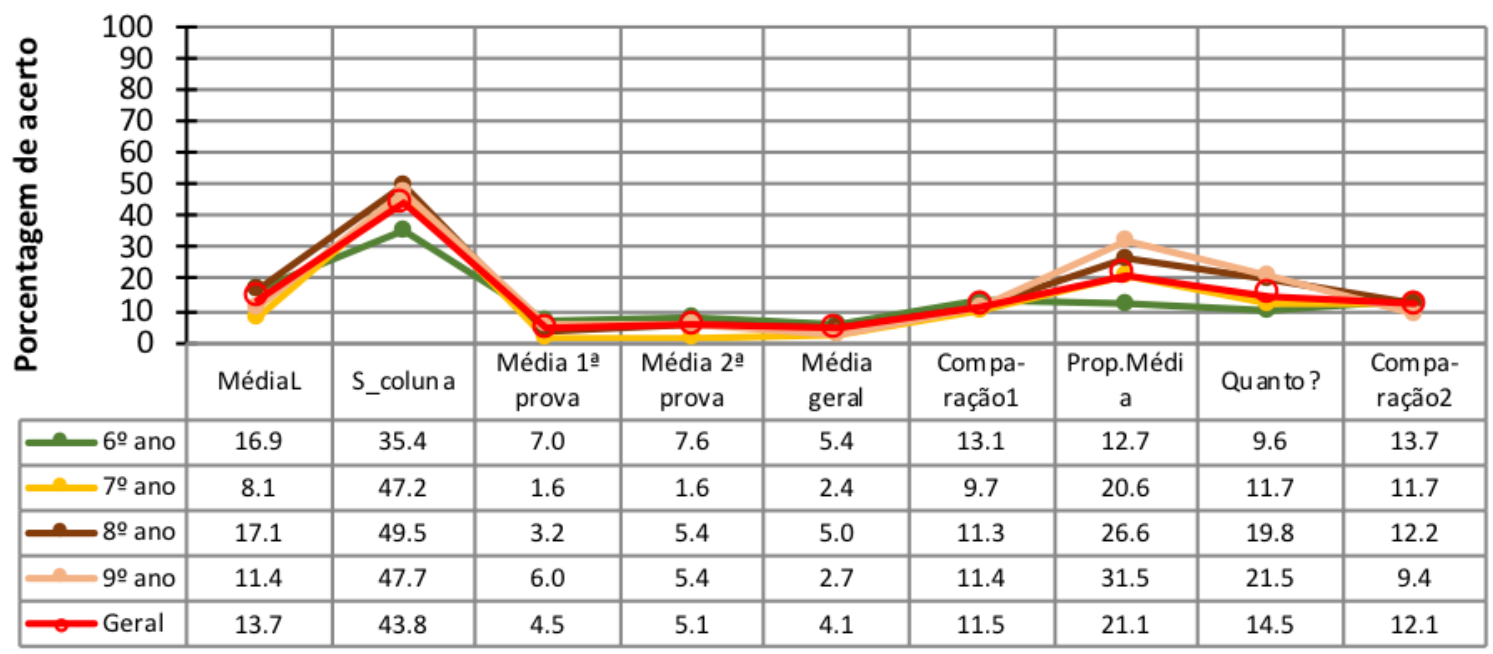

Figura 14 Porcentagem de acerto dos estudantes dos anos finais na Questão 2, por ano escolar. Fonte: acervo do D-Estat.

Quando elaboramos a questão acreditávamos que os estudantes teriam muita familiaridade com o cálculo da média das notas em representação tabular. Na Figura 15 apresentamos os extratos da resolução de dois estudantes, em que observamos que os estudantes realizam as somas por linhas (notas de cada estudante) e colunas (notas em cada prova) de forma correta, mas o da esquerda aparentemente somou as três colunas e dividiu por três, que poderia ser um indício do conceito de média, mas que ainda precisa de instrução. $\mathrm{O}$ estudante da direita juntou os dois números, considerando a nota na primeira prova como o inteiro e a nota na segunda prova como a parte decimal, sinalizando que não tem noção do conceito de média.
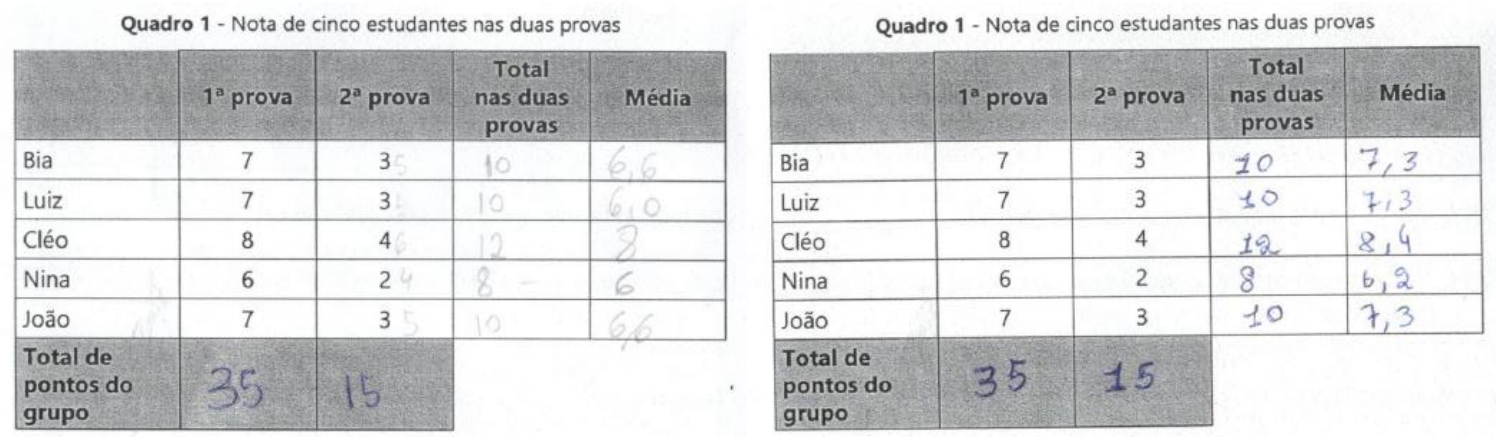

Figura 15 - Solução de dois estudantes do $9^{\circ}$ ano na determinação da média por linha.

Fonte: acervo do D-Estat.

A queda no desempenho, quando comparada à Questão 1, parece indicar que os estudantes não possuem familiaridade com dados no formato de tabelas. Observamos que Luna e Carvalho (2019) verificaram que a apresentação dos dados em gráficos atrapalhou o desempenho dos estudantes. No presente estudo parece que os estudantes não estão acostumados a trabalhar com dados em representação tabular.

A Questão 3 era similar a dos anos iniciais, porém em uma TDF de dupla entrada (Figura 16). Solicitava 10 tarefas de maior complexidade, pois exigia um nível avançado de 
DOI: $10.20396 /$ zet.v28i0.8656917

leitura de dados: a soma por linha (Tot-linha); a soma das colunas (Tot-C1, Tot-C2 e TotC3); a frequência relativa de cachorro para as meninas $(\% \mathrm{~F})$; para os meninos $(\% \mathrm{M})$, estabelecer relação entre essas frequências relativas (Relação1); indicar a relação (Qual1), a percepção da relação entre as variáveis (Relação2) e indicar o tipo de relação (Qual2).

Na Figura 17 podemos observar que a soma por linhas foi melhor executada do que a soma por colunas, e essa execução foi melhor realizada conforme o ano de escolaridade dos estudantes. Pouquíssimos estudantes conseguiram calcular a frequência relativa, a maioria repetiu a frequência absoluta acrescida do símbolo \%, sendo que porcentagem está prevista no currículo desde o $5^{\circ}$ ano. Poucos estudantes conseguiram ver a relação entre as variáveis, e quando explicitaram tal relação, as justificativas eram dadas a partir de suas crenças e não a partir dos dados.

\begin{tabular}{|c|c|c|c|c|}
\hline \multicolumn{4}{|c|}{$\begin{array}{l}\text { Quadro 2 - Quantidade de estudantes por gênero, } \\
\text { segundo o animal de estimação favorito }\end{array}$} & \multirow{3}{*}{$\begin{array}{l}\text { Q3a. Preencha a tabela com o total com que cada } \\
\text { animal foi escolhido. } \\
\text { Q3b. Quantos meninos responderam à pesquisa? } \\
\text { Quantas meninas? Ao todo, quantos estudantes } \\
\text { responderam à pesquisa? }\end{array}$} \\
\hline \multirow{2}{*}{$\begin{array}{l}\text { Animal de } \\
\text { estimação favorito }\end{array}$} & \multicolumn{2}{|c|}{ Gênero } & \multirow{2}{*}{ otal } & \\
\hline & Menino & Menina & & \\
\hline Gato & 0 & 75 & & \multirow{3}{*}{$\begin{array}{l}\text { Q3c. Quanto por cento das meninas escolheram } \\
\text { Cachorro? } \\
\text { Q3d. Quanto por cento dos meninos escolheram } \\
\text { Cachorro? }\end{array}$} \\
\hline Passarinho & 15 & 15 & & \\
\hline Cachorro & 25 & 50 & & \\
\hline $\begin{array}{l}\text { Outros (macaco, } \\
\text { jabuti etc.) }\end{array}$ & 5 & 5 & & \multirow{3}{*}{$\begin{array}{l}\text { Q3e. Analisando os dados da tabela e as porcentagens } \\
\text { calculadas, podemos afirmar que as meninas } \\
\text { preferem cachorro, mais do que os meninos? ( )Não ( } \\
\text { )Sim. Por quê? }\end{array}$} \\
\hline Nenhum & 5 & 5 & & \\
\hline \multicolumn{4}{|l|}{ Total de es } & \\
\hline & & & & $\begin{array}{l}\text { Q3f. Analisando os dados da tabela, na sua opinião, } \\
\text { existem evidências de relação entre o animal de } \\
\text { estimação favorito e o fato de ser menino ou menina? } \\
\text { ( )Não ( )Sim. Por quê? }\end{array}$ \\
\hline
\end{tabular}

Figura 16 - Enunciado da Questão 3 dos anos finais. Fonte: acervo do D-Estat.

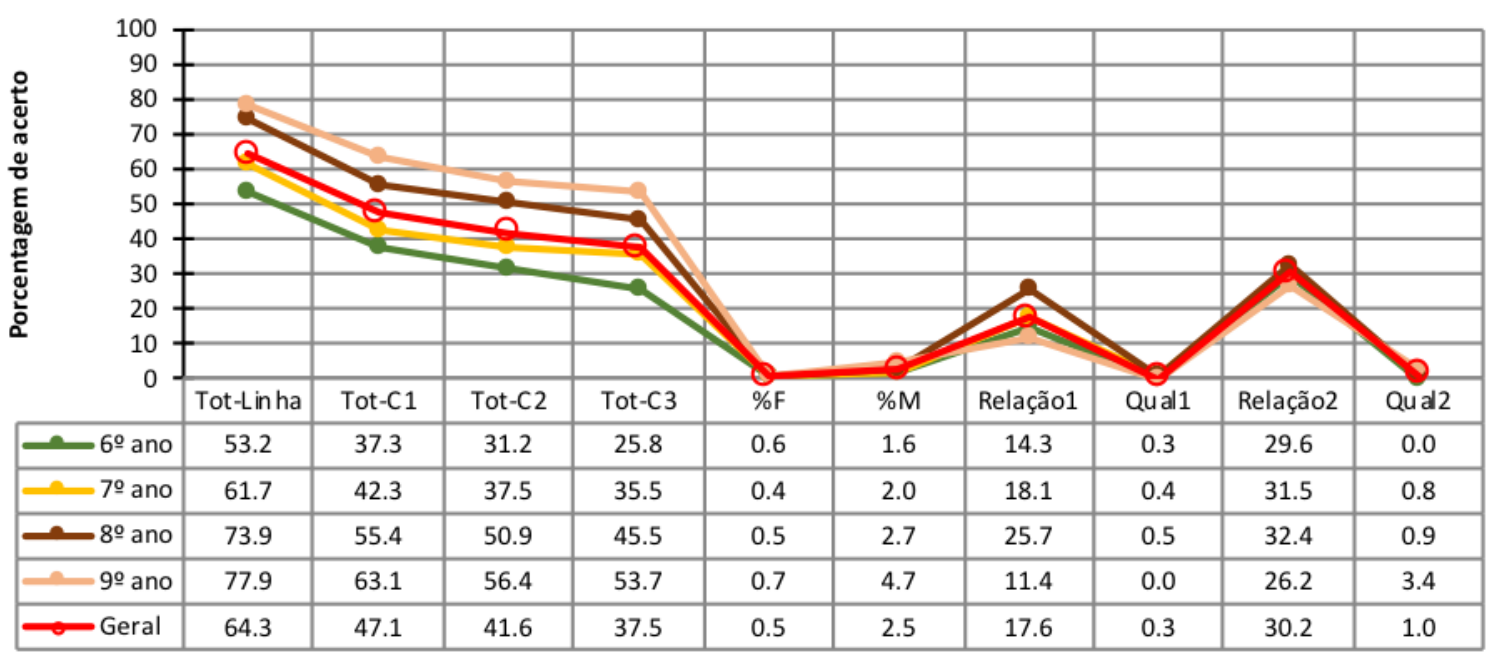

Figura 17 - Porcentagem de acerto dos estudantes dos anos finais na Questão 3, por ano escolar. 
Finalizando a análise do desempenho dos estudantes dos anos finais apresentamos a Figura 18. Observamos que o percentual de acertos cai significativamente em relação ao dos dois outros ciclos, e o de respostas em branco aumenta consideravelmente. Os itens que apresentaram maior percentual de respostas em branco, superior a $50 \%$, foram os que solicitavam o nome do conceito estatístico, média, mediana e a identificação da relação entre o gênero e o animal de estimação favorito. Acreditamos que também esses eram os itens esperados a causarem mais ausências de respostas corretas, pois usualmente as atividades escolares não cobram o nome dos conceitos e tampouco exigem mais do que o nível elementar de interpretação de uma tabela ou gráfico.

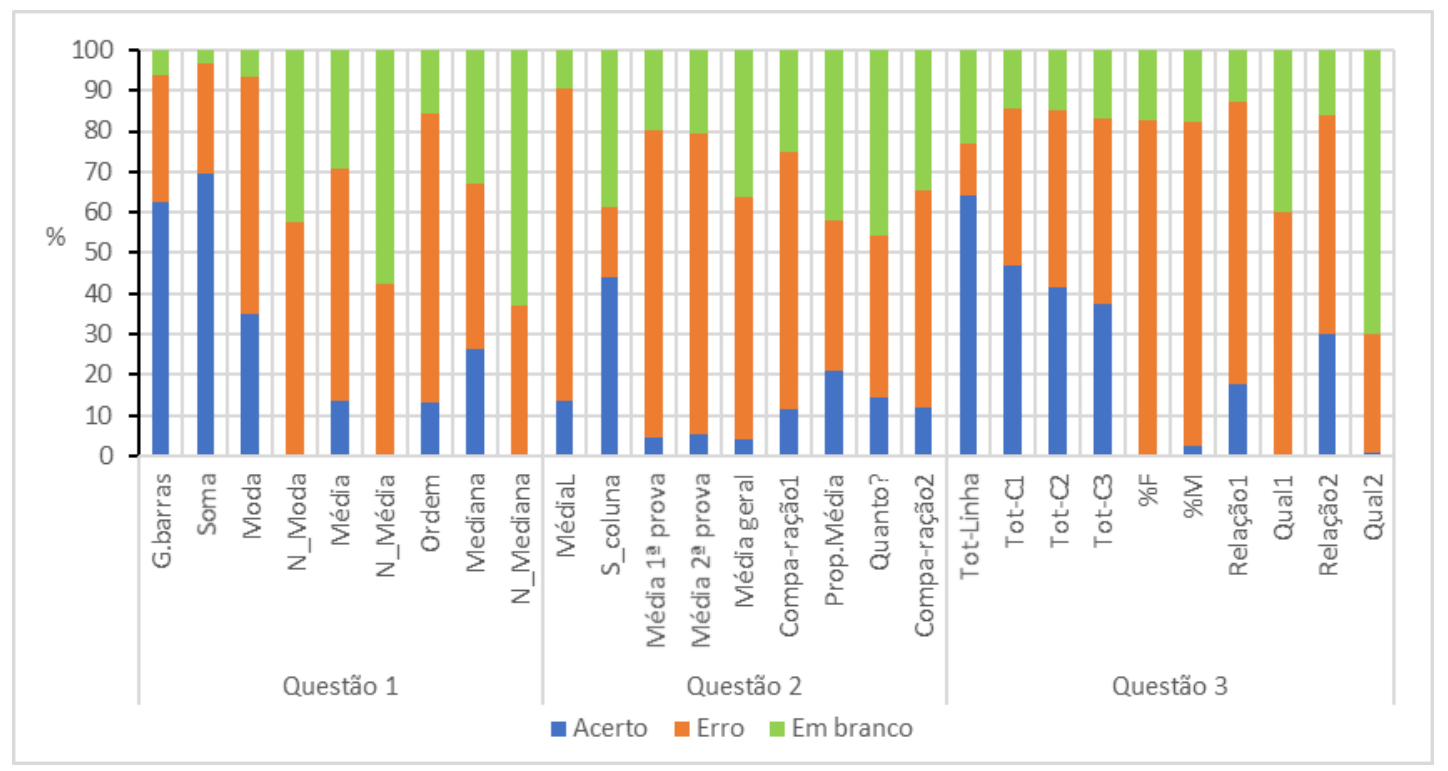

Figura 18 - Distribuição percentual do acerto, erro e em branco, por item, dos estudantes dos anos finais. Fonte: acervo do D-Estat.

\section{Análise global do desempenho dos estudantes do Ensino Fundamental}

Nesta seção traçamos paralelos a respeito do desempenho nos três ciclos de ensino. Na Questão 1 podemos observar que, em geral há um crescimento do desempenho ao longo dos anos escolares dentro de cada ciclo, porém há uma queda de um ciclo para outro, em especial, nos anos finais, particularmente no $9^{\circ}$ ano.

Na conversão de dados da língua materna (anos iniciais) e lista (anos finais) para a representação gráfica (G.Barras) verificamos um franco crescimento do desempenho nos anos iniciais, passando de menos de $30 \%$, no $1^{\circ}$ ano, para pouco mais de $80 \%$ no $5^{\circ}$ ano; porém, observamos uma estagnação nos anos finais, no patamar de $60 \%$, com exceção do $8^{\circ}$ ano, que atinge cerca de $75 \%$, mas ainda assim inferior ao desempenho atingido pelo $5^{\circ}$ ano.

Dentre os principais erros cometidos na conversão dos dados da língua materna para a representação gráfica pelos estudantes apresentamos os da Figura 19. Verificamos que nos anos iniciais, alguns estudantes mesmo pintando a quantidade correta de retângulos, pintaram 
DOI: $10.20396 /$ zet.v28i0.8656917

algumas barras sem começar a escala no zero (19a), evidenciando que não conseguem ainda relacionar o eixo das ordenadas com a quantidade de retângulos em cada barra. Outros pintaram as barras juntas (19b), na ordem em que apareceram os dados, porém não conseguiram relacionar o nome de cada criança com a coluna; nos anos finais alguns alunos tentaram fazer um gráfico de linhas (19c) e construíram um gráfico de "faixas" (19d), dentre outros. Estes resultados nos fazem concordar com as conclusões de Carvalho, Oliveira e Monteiro (2019) sobre a necessidade de os professores enfatizarem a sistematização das informações estatísticas e o uso de escala nos gráficos de barras.

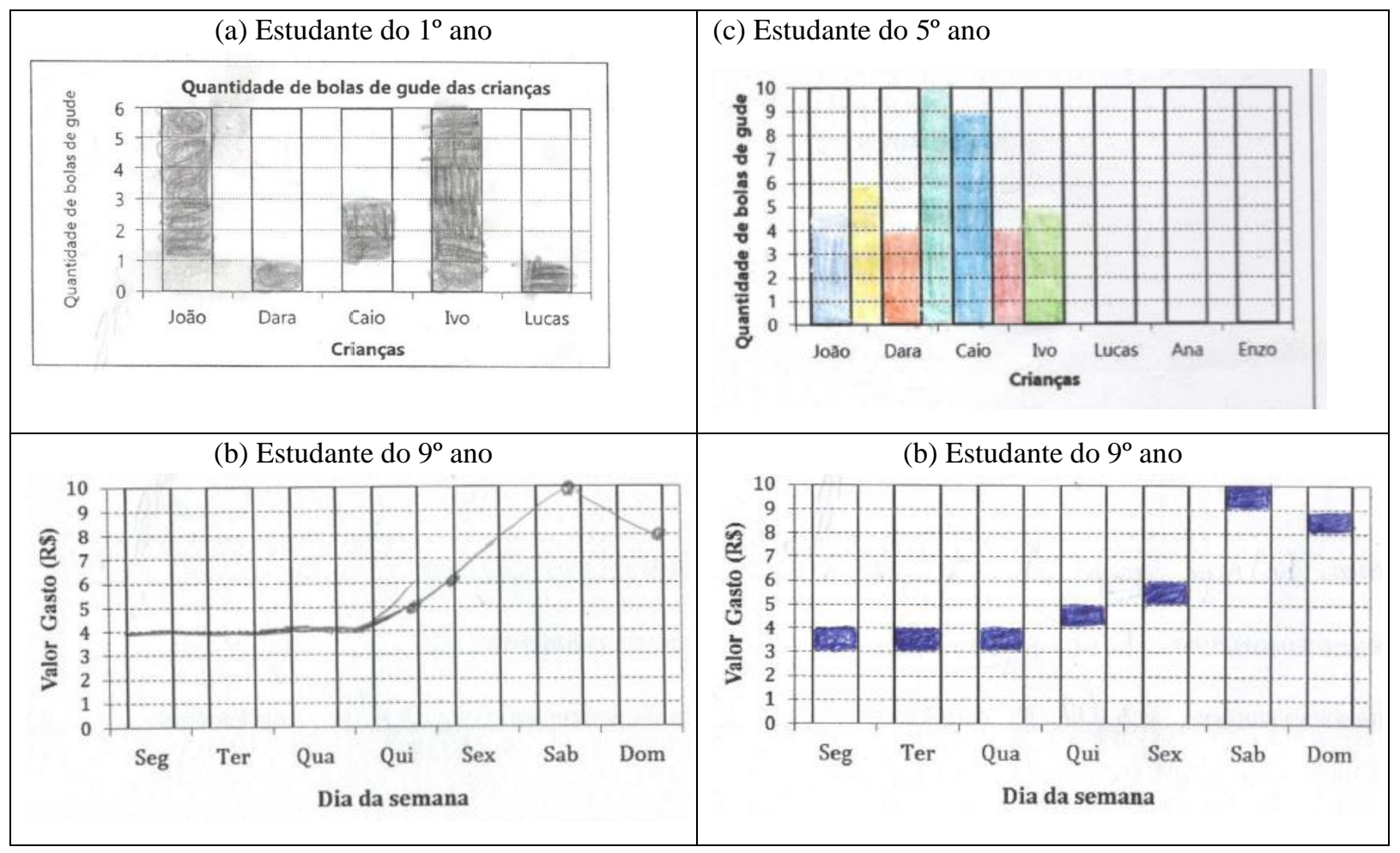

Figura 19 - Exemplos de erros na conversão de dados para o gráfico de barras. Fonte: acervo do D-Estat.

Com relação à Moda, mais de $60 \%$ dos estudantes dos anos iniciais conseguiram identificar o valor que mais se repetia, nos anos finais isso não foi atingido no $9^{\circ}$ ano, que ao invés de responderem que o valor gasto com maior frequência era $R \$ 4,00$, responderam o valor máximo dos gastos, $\mathrm{R} \$ 10,00$. Da mesma forma no $5^{\circ}$ ano, ao invés de responderem que a quantidade de bolas de gude que mais se repetia era 4, responderam a quantidade máxima, que era 10 bolas. Esses resultados são discordantes com o que se espera que ocorra: que o maior nível de escolaridade propicie um maior desempenho, como ocorridos no estudo de Luna e Carvalho (2019).

Quanto a soma (Figura 20) verificamos que o desempenho do $1^{\circ}$ ao $3^{\circ}$ ano passou de $40 \%$ a $60 \%$, sendo que muitos estudantes utilizaram representação pictórica como mostra a Figura 20a; o desempenho dos estudantes do $4^{\circ}$ e $5^{\circ}$ anos ficou em torno de $50 \%$, e os dos anos finais passou de $60 \%$ no $6^{\circ}$ ano, para $80 \%$ no $8^{\circ}$ ano e $9^{\circ}$ ano. Muitos estudantes 
DOI: $10.20396 /$ zet.v28i0.8656917

registraram diversos tipos de agrupamento, sendo que a maioria desses realizaram o cálculo correto (20d). Na Figura 20b e 20c ilustramos o erro de cálculo.

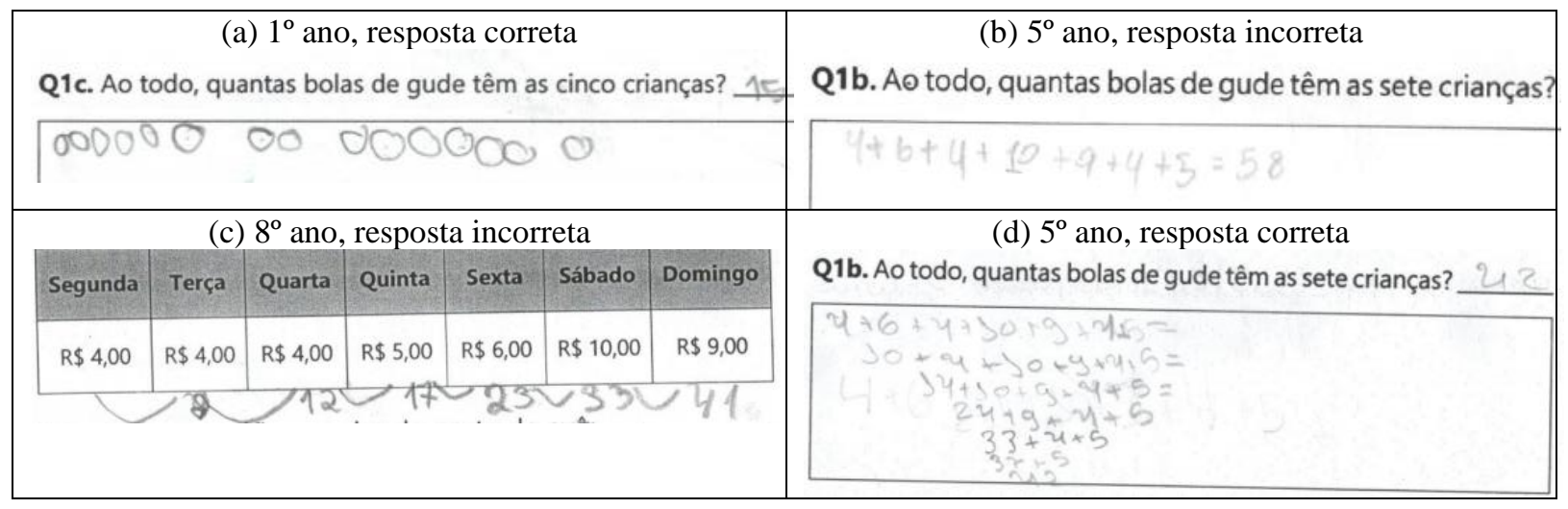

Figura 20 - Registros da soma de alguns estudantes.

Fonte: acervo do D-Estat.

Com relação à média vemos que há uma queda substancial no desempenho de um ciclo para outro, sendo que os números envolvidos eram pequenos e a divisão exata, o que permitia o uso de estratégias alternativas ao algoritmo da divisão, como os exemplificados na Figura 21. Observamos que, no geral, o índice de acertos no $1^{\circ}$ ciclo foi de $10 \%$ no $1^{\circ}$ ano até $45 \%$ no $3^{\circ}$ ano; no $4^{\circ}$ ano ficou em torno de $25 \%$ e no $5^{\circ}$ ano em $30 \%$. Já nos anos finais esse índice passou de $5 \%$ no $6^{\circ}$ ano para $30 \%$ no $8^{\circ}$ e caiu para $20 \%$ no $9^{\circ}$ ano.

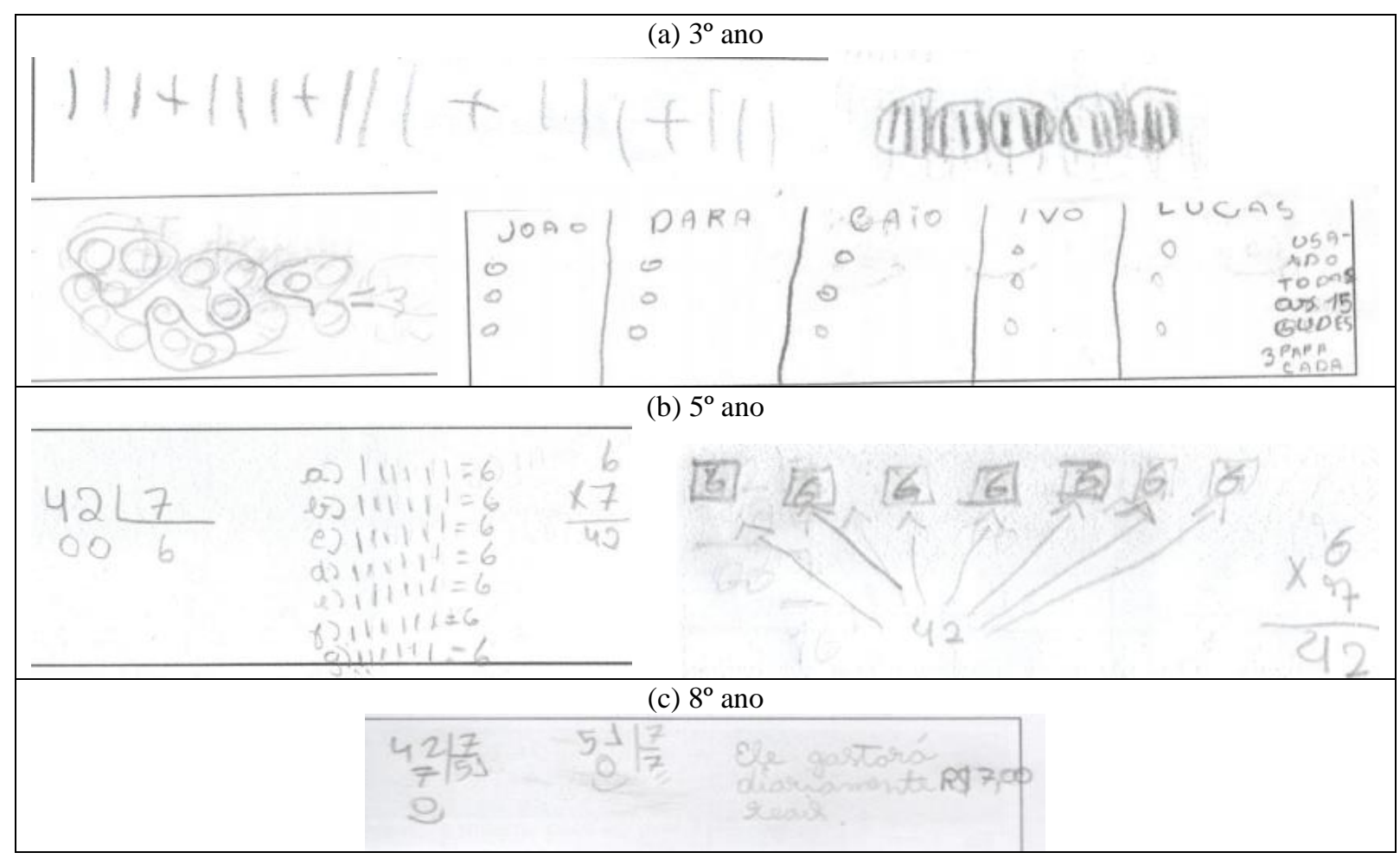

Figura 21 - Registros da média de alguns estudantes.

Fonte: acervo do D-Estat. 
Na Figura 21a observamos que os estudantes do $3^{\circ}$ ano recorreram a diversos tipos de representações pictóricas; os estudantes do $4^{\circ}$ e $5^{\circ}$ anos utilizaram uma mescla entre $o$ algoritmo da divisão e a representação com desenhos (Figura 21b) e, em geral, os estudantes dos anos finais, só registraram o resultado final e a maioria errou. Na Figura 21c ilustramos a dificuldade de um estudante do $8^{\circ}$ ano no algoritmo da divisão, comprometendo o cálculo da média, como nos resultados encontrados por Luna e Carvalho (2019).

Com relação ao desempenho na Questão 2, cujos dados estavam apresentados em formato tabular, podemos observar que, no $1^{\circ}$ ciclo, após uma estagnação nos dois primeiros anos há um crescimento significativo no $3^{\circ}$ ano; uma queda substancial no $4^{\circ}$ e $5^{\circ}$ ano e uma queda maior ainda nos anos finais.

Observando que no Ciclo da alfabetização era uma tabela simples, com quatro números, cuja soma era 12 , os estudantes do $3^{\circ}$ ano se saíram relativamente bem na soma e na média, muitas vezes recorrendo a divisão em partes iguais e de forma pictórica, como mostra a Figura 22.

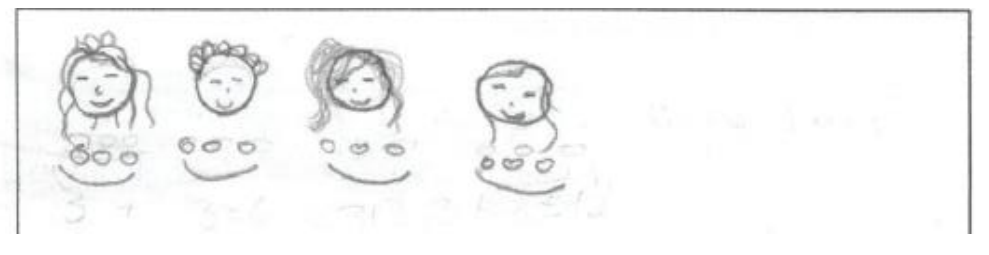

Figura 22 - Registro do cálculo da média por um estudante do $3^{\circ}$ ano.

Fonte: acervo do D-Estat.

Com relação à mediana, podemos verificar que alguns estudantes ordenaram os números de forma correta (Figura 23), mas praticamente nenhum conseguiu perceber que a mediana estava entre os dois valores que ocupavam as posições centrais. Este resultado é concordante com os resultados de Mayén et al. (2007) que verificaram que estudantes mexicanos e espanhóis também encontraram dificuldade para determinar a mediana pela indeterminação produzida por ter dois valores centrais. Além disso, afirmar que a mediana é 16 demonstra que o estudante não sabe que as MTC só podem tomar valores entre os valores mínimo e máximo.

\begin{tabular}{|c|c|c|c|}
\hline $1^{\text {a }}$ posição & $2^{\mathrm{a}}$ posição & $3^{\mathrm{a}}$ posição & $4^{a}$ posiç Q2d. Qual é a quantidade de brigadeiros que ocupa a posição central? \\
\hline 0 & 8 & 9 & 1116 ave e Damingo. \\
\hline
\end{tabular}

Figura 23 - Ordenação e tentativa de determinação da mediana de um estudante do $5^{\circ}$ ano. Fonte: acervo do D-Estat.

Com relação a Questão 3 verificamos que na extração da moda (identificar o máximo na TDF), os estudantes do $4^{\circ}$ ano tem o pior desempenho e os do $5^{\circ}$ empatam com os do $3^{\circ}$ ano. Isto é preocupante, pois conforme Curcio (1989) trata-se de uma leitura de nível elementar. Quanto à soma, observamos que são seis números mudando apenas a ordem de 
grandeza, portanto a queda no $4^{\circ}$ e $5^{\circ}$ ano não se justifica. Igualmente, o desempenho dos anos finais são preocupantes.

\section{Considerações finais}

Os resultados da presente investigação são bastante preocupantes, tendo em vista que desde 1997 foram inseridos os conteúdos de Estatística na Educação Básica, mas a maioria dos estudantes não sabe identificar a nomenclatura ao determinar média, mediana e moda. Os resultados indicam que os estudantes não estão familiarizados com a apresentação de dados em representação tabular, nem com a representação gráfica, corroborando os resultados de estudos recentes (Luna \& Carvalho, 2019; Carvalho, Oliveira \& Monteiro, 2019).

O nível de leitura das tabelas e gráficos pelos estudantes não passa do elementar, conforme classificação de Curcio (1989) e Wainer (2002). O estudante confundir a média com o valor mais frequente (moda), com o valor máximo ou com a soma, também foi relatada por outras pesquisas (Cobo \& Batanero, 2004 e Mayén et al., 2007).

Os resultados mostram que os estudantes apresentam limitações com as operações fundamentais (adição e divisão) e compreensão de leitura, que são componentes do letramento estatístico (Gal, 2002).

Como limitações do estudo informamos que as escolas parceiras, nos últimos anos, vêm sofrendo com a falta e mudanças de professores de Matemática, greves e paralisações. Também observamos que muitos estudantes, especialmente, dos anos finais deixaram questões em branco. Todavia, este levantamento também foi realizado em escolas do Ceará, Natal e São Paulo, o que permitirá verificar o efeito local. Além disso, estamos trabalhando com os professores dessas escolas há quase dois anos e está previsto um novo levantamento em 2020, quando esperamos resultados mais promissores.

Finalizando, reiteramos a necessidade de elaboração de sequências de ensino que abordem temas de interesse dos estudantes como as propostas por Santana (2006), que possibilitem o uso de diferentes tipos de representação e registros como as apresentadas por Nascimento, Paula e Carneiro (2018) para contribuir com a aprendizagem dos conceitos estatísticos, mediar conflitos, tomar decisões pessoais ou coletivas como ressaltado por Teixeira (2006) e desenvolver uma postura inquisidora, fazendo uso do senso crítico como postulado por Gal (2002), Skovsmose (2008) e Sanches e Branches (2019).

\section{Referências}

Campos, C. R., Wodewotzki, M. L. L. \& Jacobini, O. R. (2013). Educação Estatística Teoria e prática em ambientes de modelagem matemática. Belo Horizonte: Autêntica. 
DOI: $10.20396 /$ zet.v28i0.8656917

Carvalho, L. M. T. L. de, Oliveira, S. A. P. de, \& Monteiro, C. E. F. (2019). Possibilidades da Educação Estatística como forma de análise crítica da realidade na escola indígena. Roteiro, 44(2), 1-20.

Cazorla, I. M. \& Oliveira, M. S. (2010). Para Saber mais. In I. Cazorla \& E. Santana (Orgs.). Do Tratamento da Informação ao Letramento Estatístico (pp. 113-144). Itabuna: Via Litterarum.

Cazorla, I. M. \& Santana, E. (2010). Do Tratamento da Informação ao Letramento Estatístico. Itabuna. Via Litterarum.

Cazorla, I. M., Santana. E. R. S. \& Utsumi, M. C. (2019). O campo conceitual da média aritmética: uma primeira aproximação. Revemat, 14 (Edição Especial Educação Estatística), 1-21.

Curcio, F. R. (1989). Developing graph comprehension. Virginia: National Council of Teachers of Mathematics.

Gal, I. (2002). Adults' Statistical Literacy: Meanings, Components, Responsibilities. In: International Statistical Review, $1-25$.

Luna, L. C. \& Carvalho, J. I. F. (2019). “Oi, Quem está olhando minhas estatísticas?” - Uma discussão do desempenho de estudantes da Educação Básica sobre média aritmética. Amazônia: Revista de Educação em Ciências e Matemáticas, 15(33), 151-166.

Mayén, S., Cobo, B., Batanero, C. \& Balderas, P. (2007). Comprensión de las medidas de posición central en estudiantes mexicanos de bachillerato. Unión, 9, 187-201

Ministério da Educação (MEC). (1997). Parâmetros Curriculares Nacionais (PCN). Matemática.1 e 2 ciclos. Brasília: MEC, Secretaria de Ensino Fundamental.

Ministério da Educação (MEC). (1998). Parâmetros Curriculares Nacionais: Matemática. Brasília: MEC, Secretaria de Educação Fundamental.

Ministério da Educação (MEC). (2018). Base Nacional Comum (BNCC). Disponível em: http://basenacionalcomum.mec.gov.br/wpcontent/uploads/2018/12/BNCC_19dez2018_si te.pdf.

Nascimento, M. M., Paula, M. \& Catarino, P. (2018). Sítio do pica-pau amarelo: uma atividade de Estatística no $2 .^{\circ}$ ciclo do ensino básico português. Indagatio Didactica, 10(4), 107-117.

Santana, E. \& Cazorla, I. (2018). Desenvolvimento profissional de professores que ensinam Matemática: D-Estat. Projeto de pesquisa. Universidade Estadual de Santa Cruz, IlhéusBA.

Santana, M. de S. (2016). Traduzindo pensamento e letramento estatístico em atividades para sala de aula: construção de um produto educacional. Bolema, 30(56), 1165-1187.

Santos, R. M. dos \& Branches, M. V. (2019). Problemas identificados em gráficos estatísticos publicados nos meios de comunicação. Amazônia: Revista de Educação em Ciências e Matemáticas, 15(33), 201-218.

Skovsmose, O. (2008). Desafios da educação matemática crítica [Challenges of Critical Mathematics Education]. São Paulo: Papirus. 
DOI: $10.20396 /$ zet.v28i0.8656917

Teixeira, P. J. M. (2016). Os PCN e o bloco Tratamento da Informação: algumas possibilidades teórico-metodológicas para a sala de aula da Educação Básica. Remat, 2(2), 72-91.

Wainer, H. (1992). Understanding graph and tables. Educational Researcher, 21(1), 14-23. 